TITLE: DEVELOPMENT OF AN XUV-IR FREE-ELECTRON LASER USER FACILITY FOR SCIENTIFIC RESEARCH AND INDUSTRIAL APPLICATIONS

\author{
AUTHOR(S): B.E. Newnam, R.W. Warren, S.D. Conradson, J.C. Goldstein, \\ B.D. McVey, H.J. Schmitt, C.J. Elliott, M.J. Burns, \\ B.E. Carlsten, K.-C. Chan, W.J. Johnson, T.-S. Wang, \\ R.L. Sheffield, K.L. Meier, R.H. Olsher, M.L. Scott, \\ SUBMITTED TO: \\ and J.E. Griggs \\ Proceedings of the Short Wavelength Radiation Sources Conference, \\ Society of Photo-Optical Instrumentation Engineers \\ SPIE Volume 1552, San Francisco, CA, July 1991
}

By acceptance of this articto the publisher recogrizes that the U.S. Governement retains a nonectusive, royalty-tres license to publish of reprocuce the publistred form of this contribution of bo allow others to do so, for US. Government purposes.

The Los Alames National Laboratory requests that the publisher identity this articts as work pentormed under the auspices of tho U.S. Departmert of Energy

แ0S A

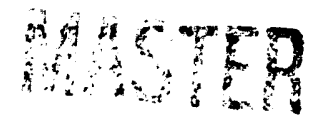




\title{
Development of an XUV-IR free-electron laser user facility for scientific research and industrial applications*
}

\author{
B. E. Newnam, R. W. Warren, S. D. Conradson, J. C. Goldstein, \\ B. D. McVey, M. J. Schmitt, C. J. Elliott, M. J. Burns, \\ B. E. Carlsten, K.-C. Chan, W. J. Johnson, T.-S. Wang, \\ R. L. Sheffield, K. L. Meier, R. H. Olsher, M. L. Scott, \\ and J. E. Griggs
}

Los Alamos National Laboratory

Los Alamos, New Mexico 87545

\begin{abstract}
Los Alamos has designed and proposes to establish an XUV-IR free-electron laser (FEL) user facility for scientific research and industrial applications based on coherent radiation ranging from soft $x$-rays as short as 1 $\mathrm{nm}$ to far-infrared wavelengths as long as $100 \mu \mathrm{m}$. As the next-generation light source beyond low-emittance storage rings with undulator insertion devices, this proposed national FEL user facility should make available to researchers broadly tunable, picosecond-pulse, coherent radiation with $10^{4}$ to $10^{7}$ greater spectral flux and brightness. The facility design is based on two series of FEL oscillators including one regenerative amplifier. The primary series of seven FEL oscillators, driven by a single, 1-GeV $\mathrm{r}$ linac, spans the short-wavelength range from 1 to $600 \mathrm{~nm}$. A second $60-\mathrm{MeV}$ if linac, synchronized with the first, drives a series of three Vis/IR FEL oscillators to cover the 0.5 to $100-\mu \mathrm{m}$ range. This paper presents the motivation for such a facility arising from its inherently high power per unit bandwidth and its potential use for an array of scientific and industrial applications, describes the facility design, output parameters, and user laboratories, makes comparisons with synchrotron radiation sources, and summarizes recent technical progress that supports the technical feasibility.
\end{abstract}

\section{INTRODUCTION}

Free-electron lasers (FELs) for the vacuum-ultraviolet and soft $x$-ray spectral regions (together termed the XUV) are being developed at Los Alamos for integration into a future national XUV-IR FEL user facility for scientific experimentation and for industrial applications. ${ }^{1-5}$ Since 1984, a multi-disciplinary project team of Los Alamos scientists has been developing the theoretical basis and the requisite technologies needed to extend rf-linac-driven free-electron lasers into the extreme-ultraviolet below $100 \mathrm{~nm}$. This activity has been a natural spinoff from the DoD/SDI high-power FEL program at Los Alamos, which requires visible and near-infrared devices. The XUV-FEL project has enjoyed the sponsorship of both the DOE Officis of Basic Energy Sciences and Los Alamos Institutional Supporting R\&D.

Los Alamos work on extending FELs into the XUV began in earnest after Newnam et al. 6 and Goldstein et al. 7 determined in 1983 that if linacs needed only modest improvements to be able to meet the electron beam quality requirements for operation at wavelengths $\leq 100 \mathrm{~nm}$. Since that time, Los Alamos National Laboratory, 8-13 Stanford University, 14,15 and Boeing Aerospace and Electronics 16,17 have operated if-linac-driven FEL oscillators in the visible and near infrared for a cumulative total of several thousand hours. Experience with these systerns has provided invaluable insight and data with which to design if-linac-driven $\mathrm{FEL}$ oscillators for operation in the XUV spectral range.6,7,18-25 An important distinction of the Los Alamos IR FEL has been its very high $500-A$ peak current capability and correspondingly large single-pass optical gain from a short, 1-m undulator (250\% small-signal gain/pass at $10 \mu \mathrm{m}$ with $300-400$ A peak current). 3,10 Such are the magnitudes of the parameters that will be required to operate FEL oscillators in the XUV.26,27

"Work supported by Los Alamos National Laboratory Program Development Funds and performed under the auspices of the U.S. Department of Energy. 
To realize the potential of FEL operation in the XUV, we have concentrated on improving the state-of-the-art of the three basic components of an FEL: electron beam, magnetic undulator, and resonator mirrors. Recent experimental progress at Los Alamos and at other FEL centers supports our conviction that operation in the XUV down to $50 \mathrm{~nm}$ is ready to be implemented in the next few years followed by phased extensions down to $10 \mathrm{~nm}$ and below. Key achievements have included:

- Design, construction, and characterization of a new photocathode injector that produces electron beams 10-100 $x$ brighter than possible with thermionic cathode injectors, 12,13,28-31

- Construction of high-precision undulators (permanent-magnet and hybrid)32-34 and high-field superconducting undulators 35,36 and pulsed electromagnet wigglers 37,38 with periods $<1 \mathrm{~cm}$ and $a_{w} \sim 1$,

- Invention and implementation of R. Warren's pulsed-wire technique for sensitive detection, correction, and on-line monitoring of magnetic-field errors,39-41 and

- Design and demonstration of high-reflectance, multifacet metal mirrors needed for resonators below 100 $\mathrm{nm}$.42-44 Especially roteworthy was the attainment of $89 \%$ retroreflectance at $58 \mathrm{~nm}$ by a nine-facet $\mathrm{Al}$ reflector, which is more than a factor-of-two higher than previously exhibited by any other refiector at ihis XUV wavelength. 44

These advances are discussed in more detail in the Appendix of Section 9. In the following Section 2, we enumerate the scientific and industrial applications that are awaiting FELs in the VUV and XUV regions. Section 3 presents the FEL facility design and plans for user laboratories. Section 4 details the predicted output optical parameters of the FELs, and Section 5 compares these with third-generation synchrotron radiation sources now under construction. The development schedule for the proposed facility is discussed in Section 6 . Finally, the Appendix of Section 9 reviews the FEL technology developments that will enable FEL operation in the XUV.

\section{POTENTIAL APPLICATIONS FOR FEL SOURCES OF UV AND XUV RADIATION}

The FEL facility proposed by Los Alamos National Laboratory is designed to operate over a broad spectral range for applications requiring both XUV and IR photons from $1 \mathrm{~nm}$ to $100 \mu \mathrm{m}$. Although it will be useful for a wealth of research opportunities in the infrared, the focus of this proposed facility is primarily in the VUV/XUV range below $200 \mathrm{~nm}$ where the technical challenges are the greatest and, arguably, where FEL radiation will find greatest application. The Los Alamos facility should complement the capabilities of other existing and planned FEL user facilities, all of which operate in the visible to far infrared as indicated in Fig. 1. Among these are the operating FELs at the University of California at Santa Barbara, Stanford University, Vanderbilt University, Duke University, and the FOM-Institute for Plasmaphysics in the Netherlands. These Vis/IR FEL facilities are being used for experimental studies of a variety of scientific applications as reported in the 1989 Special Issue of the Journal of the Optical Society-B on Physics of Free-Electron Laser Applications. 45 In addition, a number of workshops have been convened to consider the possible applications for Vis-IR FEL radiation.46,47

According to experts in various scientific disciplines, numerous potential applications are awaiting the development and commissioning of FEL user facilities operating in the vacuum ultraviolet and extreme ultraviolet. The availability of several orders-of-magnitude more monochromatic photons per unit time (compared with synchrotron radiation sources) in trains of picosecond pulses will significantly impact atomic and molecular science, photochemistry, biology, physics of materials, interfaces and surfaces, and detectors and optics. The high intensities can be used to induce nonlinear physical phenomena, diagnose short-lived phenomena in low-density targets, and outshine keV plasmas in terms of spectral brightness. The greater number of photons per second will increase the signal-to-noise-ratio of experiments that heretofore could not be conducted or will provide snapshots of temporally unstable targets. The FEL applications workshop at Castelgandolfo (1984) 46 and especially the OSA Topical Conference on Free-Electron Laser Applications in the Ultraviolet held in 1988 at Cloudcroft, New Mexico 49,50 addressed the short-wavelength applications. At the Cloudcroft meeting the participants weighed the proposed applications for UV/XUV FELS against two criteria: 1) uniqueness (possible only with FEL radiation), and 2) significant improvement (applications that FELs should satisfy much better than existing photon sources). A partial listing of those applications and source requirements that can be met by an FEL is given in Table 1. 


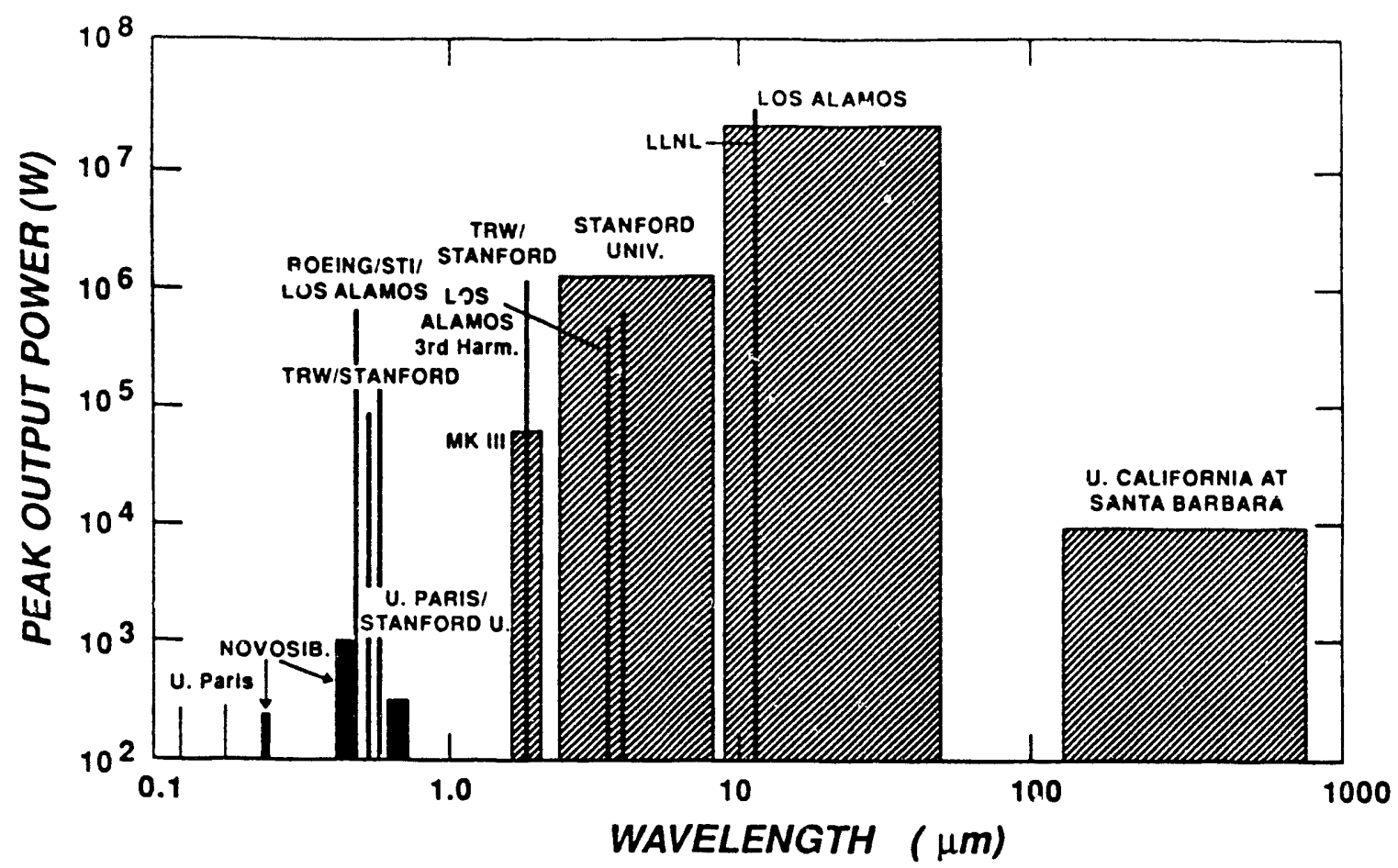

Figure 1. Successful free-electron laser operation in the near-ultraviolet to the far-infrared provides the experience base for extension below $0.1 \mu \mathrm{m}$. (The weak output at the two VUV wavelengths was coherent spontaneous emission from electrons bunched within an undulator by an external $532-\mathrm{nm}$ laser.48)

\section{Table 1. Appllcations for UV/XUV free-electron lasers and parameter requirements $\mathbf{4 9 , 5 0}$}

\section{Materials science and processing:}

- 0.1 -micron resolution XUV projection lithography $10-60 \mathrm{~nm} ; 5-10 \mathrm{~nm}$ for $0.05 \mu \mathrm{m}$ resolution

- Spin-resolved photoelectron spectroscopy to develop new magnetic materials Highest possible resolution, e.g., $1 \mathrm{meV}$ at $100 \mathrm{~nm}$

- Stimulation and analysis of VUV damage of amorphous dielectrics (e.g. laser gyro lifetimes) Wavelengths $\leq 100 \mathrm{~nm}$

- Superconductor band-gap measurements: photoelectron spectroscopy

\section{Blology and mediclne:} $V U V$ wavelengths with $\Delta \lambda / \lambda=10^{-4}-10^{-5}$ for low- $T_{C}$ materials

- Structure of macromolecules 120 - $200 \mathrm{~nm}$ for circular dichroism measurements VUV wavelengths resonant with molecular scale; polarization-resolved scattering

- Radiation effects on cells and tissue $10-100 \mathrm{~nm}$ range

- Soft-x-ray holography of living cells Single-shot, ps-pulse recordings at $44 \mathrm{~A}$

- Angiogranhy $33 \mathrm{keV}$ using Compton back scattering, $\leq$ millisec irradiation times

\section{Physlcs and chemistry:}

- Photoelectron spectroscopy of actinide band structure $\Delta \lambda \lambda=10^{-4}$ to $10^{-5}$ at $100 \mathrm{eV} \& 40 \mathrm{eV}$

- Photofluorescent measurement of metallic cluster properties $10^{18}-10^{19}$ photons/sec, $\Delta \lambda \lambda<10^{-3}$

- Photoionization spectroscopy of gases and trace amounts of free radicals $10^{18}-10^{19}$ photons/sec, $\Delta \lambda \lambda \sim 10^{-4}-10^{-6}$ 
Potential industrial applications cited at Cloudcroft included XUV-FEL photolithography for commercial production of gigabit integrated circuits and photochemical processing. In a review presented at the 1991 International FEL Conference in Santa Fe, New Mexico, C. Yamanaka51 added materials surface processing, isotope photochemistry, and group chemical separation for reprocessing nuclear fuels to the list of possibilities.

\section{PROPOSED XUV-IR FEL USER FACILITY}

\subsection{FEL configuration}

The FEL facility design proposed by Los Alamos uses one high-energy $n$ linac ( $\leq 1 \mathrm{GeV}$ ) to drive a series of seven FEL oscillators that will produce trains of coherent, picosecond pulses spanning the spectral range from 1 to $600 \mathrm{~nm}$. A second series of three FEL oscillators, driven by a separate $60-\mathrm{MeV} \mathrm{n}$ linac synchronized with the first, will produce wavelengths from the visible to the far infrared from $0.5 \mu \mathrm{m}$ to $100 \mu \mathrm{m}$. Rf linacs are preferred for this facility because they offer several advantages which include:

- The electrons pass through the FEL only once at $\sim 109 \mathrm{~Hz}$ without the constraints imposed by storing a recirculating beam.

- The linac FELs can produce both high-peak and high-average output power simultaneously.

- The linear geometry allows unrestricted and variable undulator length.

- Multiple FEL oscillators can be driven in series restricted only by the available laboratory space.

- The electrons exiting the FELs can be used to generate neutrons, positrons, and gamma rays for additional experiments in synchronism, if desired, with the FEL photons.

The conceptual design of the proposed Los Alamos XUV-IR FEL facility is shown in Fig. 2. Figures 3, 4, and 5 are engineering plan sketches, and design specifics are given in Table 2. This system has several distinguishing characteristics. First, it comprises VUV-XUV FEL oscillator configurations rather than single-pass SASE amplifiers without optics. Although more complex than a simple amplifier, use of a resonator reduces the requirements on the electron beam and undulator. The single-pass gain $\left(<10^{3}\right)$ required for XUV-FEL oscillators can be achieved with 10-100X bwer electron beam brightness and undulators with half as many periods as needed for an amplifier starting from noise. The single-pass gain corresponding to exponential rise of the laser power through a long amplifier undulator would be $>10^{4}$, which would be very difficult to attain. Also, FEL resonator lengths can be adjusted to tune the spectral bandwidth either to the Fourier Transform limit of the individual ps-duration micropulses or up to several per cent via sideband generation.

The second obvious feature is that there are seven XUV-Vis FELs $(1-600 \mathrm{~nm})$ arranged in series and synchronized with three Vis-IR FELs $(0.5-100 \mu \mathrm{m})$ in series. The number of oscillators may be increased arbitrarily, consistent with the amount of accumulated energy spread and/or emittance degradation in the electron beam that can be tolerated and, of course, the available shielded laboratory space. The series configuration provides the maximum time-averaged photon flux to all users, rather than distributing the beam to parallel FELs. Only one beam dump is required for each FEL series. Third, the shortest-wavelength oscillators are ordered first in the sequence since they require the highest-quality electron beam; the gain at longer wavelengths is less affected by beam degradation. Even so, all of the oscillators are designed to perturb the electron beam energy only very slightly, with the energy-extraction efficiency being $0.1 \%$ or less. Further beam degradation by wakefield eifects in the beamline and magnetic undulator will be avoided by minimizing beam transport angles and discontinuities. Fourth, only uniform-period undulators are used to maximize optical gain.

The operating wavelengths of each of the FELs will either be tuned as a group over a $2.5 x$ range by varying the electron energy or tuned independently over a smaller $\sim 50 \%$ range by adjusting the undulator gaps. Automatic computer control of the focusing magnets will be provided to focus the electron beam properly into and out of the undulators. The spectral ranges of consecutive XUVNVis FEL oscillators, listed in Table 3, are set to partially overlap with the criterion that the multifacet resonator mirrors have at least $40 \%$ reflectance. Hole-coupled Cu metal resonator mirrors will be used for the Vis/IR FEL oscillators. A mirror gallery will distribute radiation from any of the ten FELs to each of six experimental laboratories on a scheduled basis. 


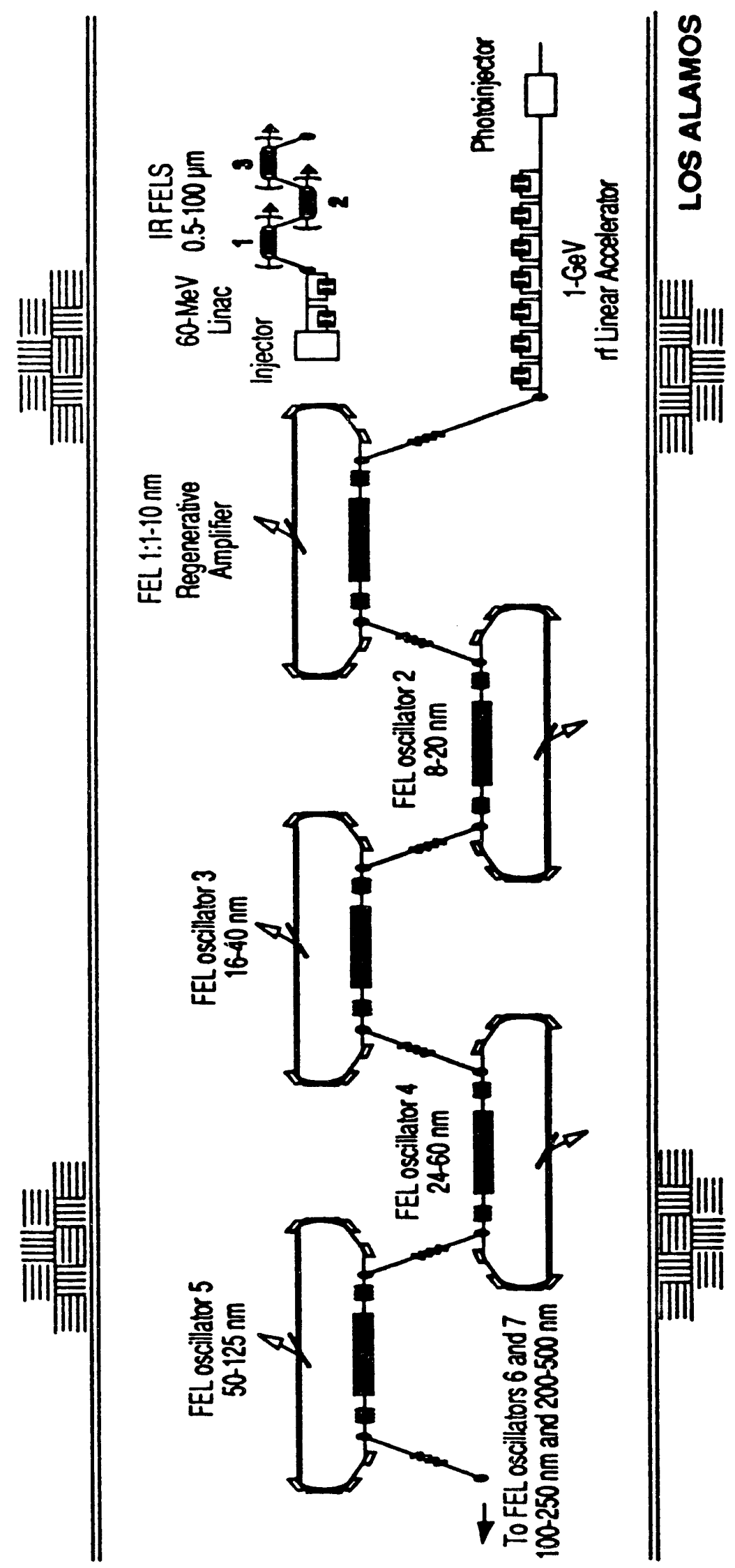

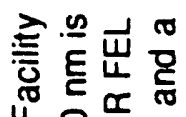

능용

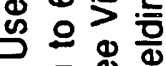

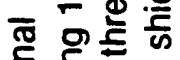

응 흗용

乙 용. 원

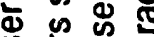

응 중

등

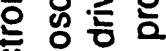

펌ㅇㅇ

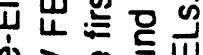

ఏ引巳 핸

ᄂ

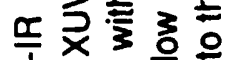

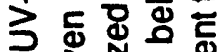

$\times$ 을엉

๕

है잉

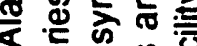

为战西

○《出

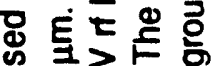

$88 \stackrel{0}{\circ}$

흔잉유용

토 옹다

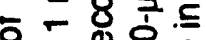

등용워 인

응늗ㅇㅇㅝ

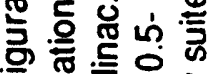

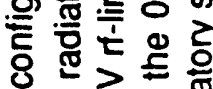

\& 응

西

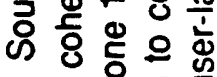

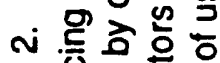

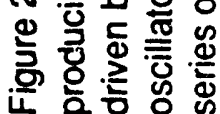




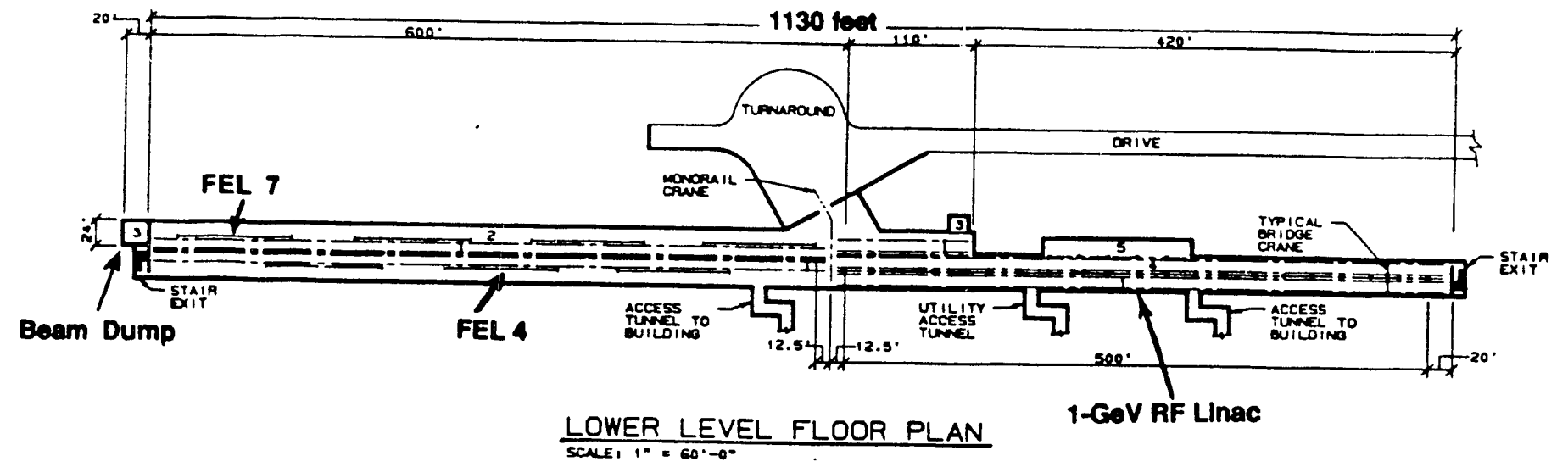

Figure 3. Lower-level floor plan of the facility which contains the FEL systems and relay optics.

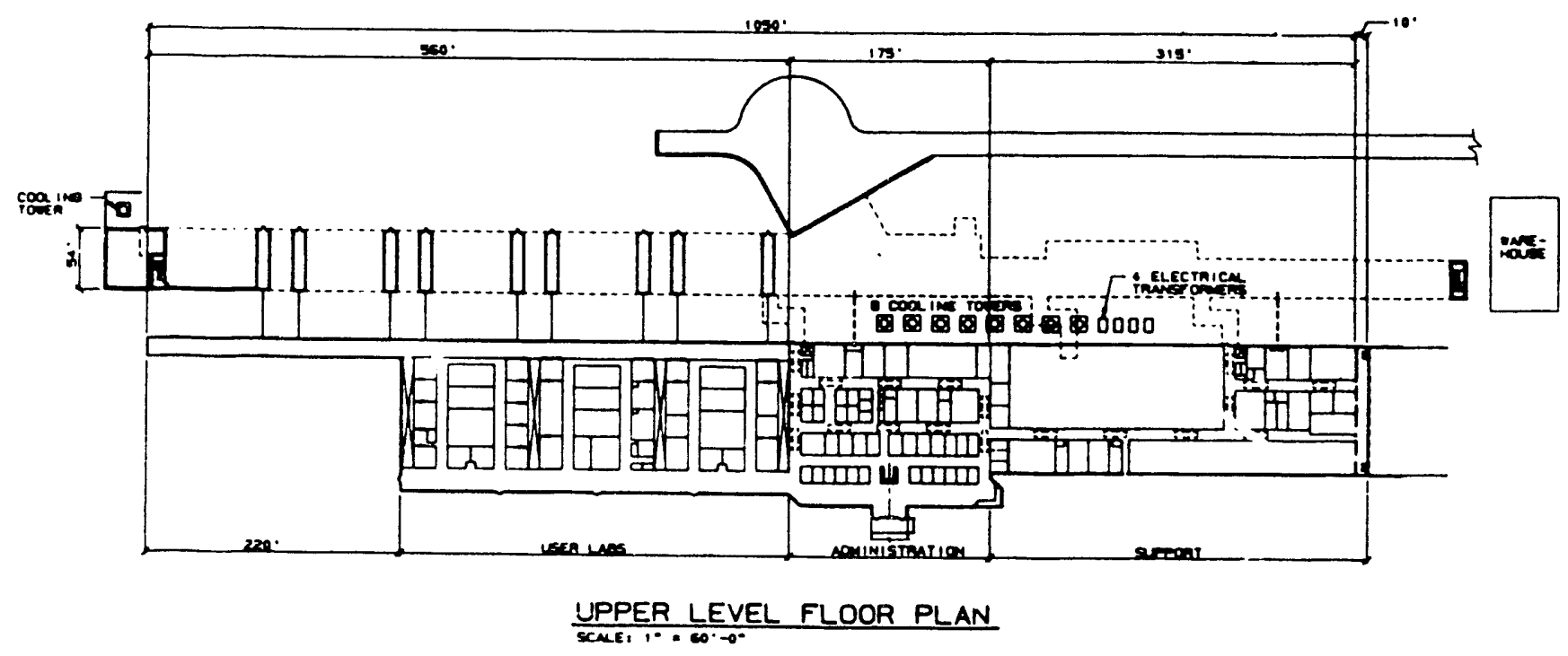

Figure 4. Upper-level floor plan of the facility which contains the user laboratories, reflector switchyard, offices, and support shops.
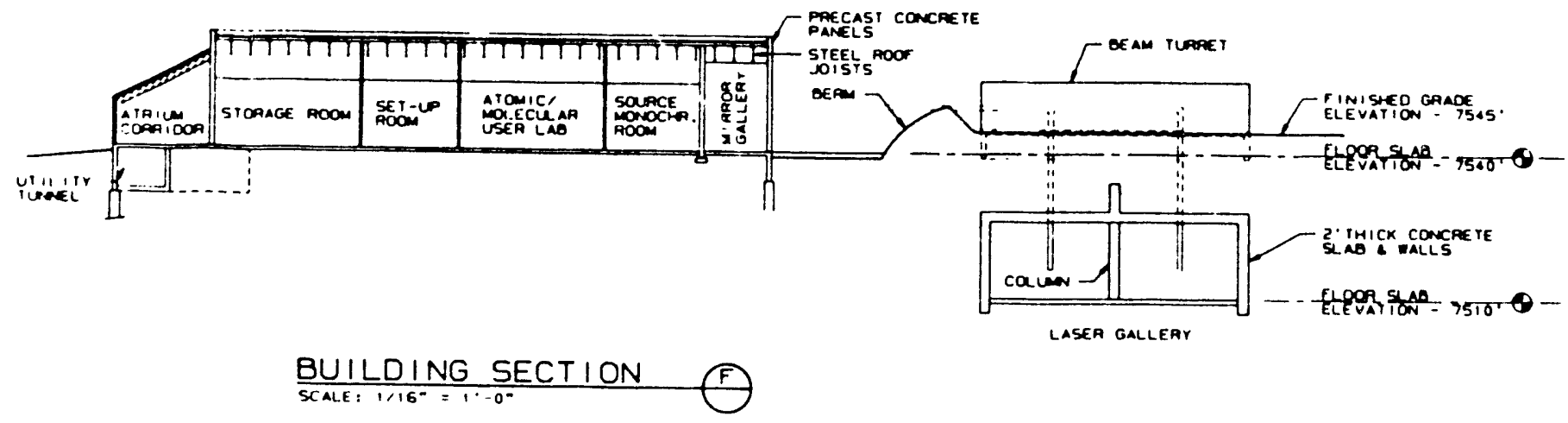

Figure 5. Cross-sectional view of the FEL vault and beam delivery to one of the user laboratories. 
Table 2. Parameters for the proposed Los Alamos if-llnac-driven XUV-IR FEL USer facllity

\section{Electron beam}

Energy:

Peak current:

Normalized emittance:

( $90 \%$ of electrons)

Energy spread: $\leq 1 \mathrm{GeV}$ for XUV/Nis FEL series, adjustable for $\lambda$ tuning $\leq 60 \mathrm{MeV}$ for Vis/IR FELs

300 to $400 \mathrm{~A}$ in $\sim 10$-ps micropulses

$10 \pi \mathrm{mm}-\mathrm{mr}$ for $<10 \mathrm{~nm}$

$30 \pi \mathrm{mm}-\mathrm{mr}$ for $>50 \mathrm{~nm}$

$0.1 \%$ to $0.2 \%$, FWHM

Undulator For 12-nm FEL; the length, period, and $K$ scale for other- $\lambda$ FELs

Length: $12 \mathrm{~m}$

Period, (Pole gap):

$1.6 \mathrm{~cm},(4.5 \mathrm{~mm})$

Peak axial field:

7.5 kG, 2-plane sextupole focusing

Undulator parameter, $\mathrm{K}$ :

1.1 , peak

Resonater mirrors Listed here for VUV/XUV FELs only; Cu and Ag coatings for Vis/IR FELs End mirrors:

$R \geq 40 \%$, multifaceted retroreflectors for VUV/XUV FELs TER metal coatings on Si for $\lambda<100 \mathrm{~nm}$.

CVD SiC for $\geq 60 \mathrm{~nm}, \mathrm{AVMgF}_{2}$ for $\geq 120 \mathrm{~nm}$

Intracavity hyperboloids:

Au coating on Si or SiC substrates

\section{Table 3. Operating ranges of the seven XUV-VIs/ble Wavelenoth FEL oscillators a}

Oscillater Number

1

2

3

4

5

6

7

\section{Operating Spectral Range}

$4.5-11 \mathrm{~nm}$

$1.5 \mathrm{~nm}$ (3rd harmonic)

$9-20 \mathrm{~nm}$

$16-40 \mathrm{~nm}$

$35-80 \mathrm{~nm}$

$50-125 \mathrm{~nm}$

$120-300 \mathrm{~nm}$

$240-600 \mathrm{~nm}$

\section{Multifacet Mirror Coating}

$\mathrm{Rh} / \mathrm{B}_{4} \mathrm{C}$ multilayer $(4.5-10 \mathrm{~nm})$ Pd or Rh $(9-11 \mathrm{~nm})$

Pd $(9-11 \mathrm{~nm})$, Rh $(10-14 \mathrm{~nm})$ $Y(14-20 \mathrm{~nm})$

$Y(16-22 \mathrm{~nm}), \mathrm{Se}(22-38 \mathrm{~nm})$ Si $(35-40 \mathrm{~nm})$

Al or crystalline Si in UHV

Al in UHV

$A l / M g F_{2}, R>80 \%$

$\mathrm{AlMgF}_{2}, \mathrm{R}>80 \%$

a Corresponding to the bandwidths over which the multifacet resonator mirror reflectance is at least $40 \%$. 
At this time, the $\mathrm{r}$ linac is designed for room-temperature operation. All of the past Los Alamos infrared FEL experiments have used an L-band $(1.3 \mathrm{GHz})$, side-coupled, standing-wave $\mathrm{f}$ linac operated at slightly above ambient temperature. Linac design calculations for advanced, standing-wave linac structures have been performed for energies from $100 \mathrm{MeV}$ to $1 \mathrm{GeV}$ for as a driver for an XUV FEL. Cryogenic and $500-\mathrm{MHz}$ superconducting (at $4 \mathrm{~K}$ ) cavity options also are being examined, because they offer potential advantages of $\mathrm{cw}$ macropulse operation and improved pulse-to-pulse power and wavelength stability. Another advantage is the lower net electrical cost due to less power dissipation in the linac structure. However, the capability of either of these alternate configurations to provide several-hundred amperes of peak current with high beam brightness must yet be demonstrated. This will require adequate damping of higher-order modes which, according to $\mathrm{G}$. Neil, et al. 52 should be demonstrated on the CEBAF superconducting linac facility within the next two years.

\subsection{User laboratories}

Due to the wide range of the proposed applications and the interest in multi-color experiments, the user laboratories of this facility have been designed for the various types of user applications rather than based on the wavelength range. An initial set of six laboratories shown in Fig. 4 has been selected and will be equipped for: 1) surface physics \& chemistry and general XUV-IR spectroscopy, 2) gas-phase atoms, ions, molecules, and beams, 3) biophysics and linear/nonlinear UV-Vis-IR spectroscopy, 4) lithography and fabrication of nanocircuitry, 5) medical procedures and studies, and 6) multiple-purpose, specialized experiments. If user demand grows as anticipated, the number of laboratory suites can be expanded along the linear dimension of the FEL facility. The high FEL photon flux will allow for short exposure times for many experiments. Therefore, associated with each exposure laboratory, we have included adjacent preparation/set-up labs for waiting experiments. Additionally, each lab will have access to radiation from any of the seven XUV-Vis FELs and three Vis-IR FELs by scheduled distribution by a reflective optical switching system. As seen in Fig. 5 , the user labs will be located on the ground surface level safely distant from the underground laser gallery. A description of each of the initial six laboratories follows. 53

Surface physics \& chemistry and general XUV spectroscopy laboratory: Surface science will be performed in a UHV chamber. This will be equipped with an electron analyzer for photoemission measurements, which must be spin sensitive for studies of magnetic materials, mass spectrometers for desorption work and sample characterization, ion guns, LEED spectrometers, and other instruments for sample preparation and analysis, and photon detectors for all regions from the IR through the XUV. Certain types of experiments can not be run on the same chamber, so more than one will be provided. Supplementary radiation sources will be available for measurements prior to the connection of the chamber to the light port. Spectral microscopy will be possible by scanning with a sample stage with the requisite spatial resolution.

Gas-phase atoms, lons, molecules, and beams laboratory: These experiments will require a source for the different types of beams and a UHV chamber which is compatible with beam experiments. Electron, mass, and light detectors on this chamber will all be necessary for acquiring the signal from the sample.

Blophysics and linear/nonlinear UV-Vis-IR spectroscopy laboratory: This laboratory will be used for measurements on samples which do not require UHV conditions, including circular and magnetic circular dichroism spectroscopy, soft $x$-ray microscopy, Raman spectroscopy, and measurements of second- and thirdharmonic generation. It will be equipped with circular dichroism and magnetic circular dichroism spectrometers, the optical components for multiple wave mixing, conventional spectrometers, and chemical and biochemical apparatus for sample preparation and character ation.

The use of these first three laboratories for advanced spectroscopic measurements, which might be conducted independently of the FEL or used in some multicolor experiments, will require additional general spectroscopy instrumentation. This will include support lasers, spectrometers, both standard and multichannel detectors, signal processing electronics, and standard optical hardware which can be used in each laboratory.

LIthography and micro/nanofabrication laboratory: Since the ultimate goal of XUV projection lithography is the fabrication of devices with $\leq 0.1$ um features, 51,54 a lithographic stepper with this capability is 
necessary. The exposure lab itself will have to be a Class-10 clean room if actual circuits are to be fabricated, and facilities for preparing and developing resists and coating wafers will be present. On-site characterization will be performed with a scanning electron microscope.

Medical procedures laboratory: This lab will be used to study the interaction of FEL radiation with tissue, both isolated from and within the body, for potential medical applications. Equipment for removing tissue from animals, treating it and maintaining its viability, and exposing it will be provided. Characterization of exposed tissue will be performed with microscopes and by chemical and biochemical analysis. Apparatus for containing and aligning live animals may also be included, as well as the corresponding clinically certified equipment for treating human subjects.

Multiple-purpose laboratory for speciallzed experiments: Many experiments, especially in the category of technological applications, will require interfacing the FEL output with elaborate equipment specific to each project, e.g., jet engines for fluid mechanics measurements or high-resolution mass spectrometers for resonance ion mass spectrometry. This lab will be dedicated to projects such as these for periods of tim.: compatible with such complicated setups. Because experimenters will need to bring their own unique equipment and instrumentation, that available for this lab will be limited to general optical apparatus.

\section{PREDICTED XUV-IR FEL OUTPUT}

We have performed 3-D numerical simulations using B. McVey's FEL code FELEX55 and its derivatives to predict the single-pass and multiple-pass gain in XUV-FEL resonators, and the spectral bandwidth, output power, and spectral brightness versus wavelength. Tables 4 and 5 provide an abbreviated summary. Over the range of high single-pass FEL gain, the predicted peak- and average-output powers, especially below $300 \mathrm{~nm}$, should sumass the capabilities of any existing, continuously tunable photon source by four to seven orders of magnitude. In addition, the spectral bandwidth may be sufficiently narrow, e.g. $\leq 10-4$ at $100 \mathrm{eV}$, that use of a monochromator may be optional for many applications.

\section{Table 4. Badlatlon propertles of the proposed LANL rf-llnac-driven XUV-IR FEL user facllity}

Micropulse duration:

Micropulse repetition rate:

Macropulse duration:

Facility wavelength span:

Spectral bandwidth: (for single, 10-ps pulses)

Polarization:

Temporal coherence:

Spatial coherence:
10-20 ps (FWHM) compressible to <2 ps

$32 \mathrm{MHz}$

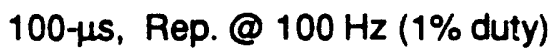

$1 \mathrm{~nm}$ to $600 \mathrm{~nm}, 7$ FEL oscillators (0.5-100 $\mu \mathrm{m}, 3$ Vis-IR FELs w/2nd 60-MeV linac)

$\geq 1 \mathrm{~cm}^{-1}$ Fourier-transform limit 10-4 w/25 klystrons, possibly $10-5$ up to $\sim 1 \%$ if sidebands are allowed

Linear, w/circular/elliptical options

Limited by micropulse Fourier trans.

Near-diffraction-limited focusability 
Table 5. Power and briohtness predictions for the proposed LANL XUV-IREEL User facllity

Peak power at target:

bw $\sim 1 \mathrm{~cm}^{-1}$, single pulse and

$\Delta \lambda / \lambda \sim 10^{-4}$, macropulse average

1- to $\geq 10 \mathrm{MW}, 12$ to $100 \mathrm{~nm}$

$\Delta \lambda \lambda \geq 1 \%, w /$ sidebands

$>20 \mathrm{MW}$, for $>100 \mathrm{~nm}$

10- to $\geq 50 \mathrm{MW}, 12$ to $100 \mathrm{~nm}$, $5 \mathrm{MW}$ at $4 \mathrm{~nm}$

Average power at target:

@ 1\% duty

1- to $>10 \mathrm{~W}, \mathrm{~W} / 0$ sidebands

30 to $200 \mathrm{~W}, \mathrm{~W} / \mathrm{sidebands}$

Photon flux at target:

from $1-600 \mathrm{~nm}$, resp.

108 - 1015 photons/10-ps pulse

1015 - 1020 photons/s, aver. @1\% duty

Spectral brightness (Peak):

$10^{28}$ photons/s/(mm-mr) 2/bw

Spectral brightness (Aver.):

1022 photons/s/(mm-mr)2/bw/@1\% duty

$\Delta \lambda \lambda \sim 10-4$, macropulse average

Electrical power cost considerations will limit the year-long average duty factor to $\sim 1 \%$ for ambienttemperature linac structures, but occasional operation at $\geq 10 \%$ duty is feasible with proper cooling of the accelerator cavities, and $100 \%$ duty may be possible if either a cryogenic or a superconducting linac design is adopted. Practically, the duty factor will be limited by laser-induced thermal distortion of the FEL resonator mirrors. 56 The latter limitation can be avoided entirely if exponential single-pass gain (net $\sim 104$ ) can be realized in FEL amplifiers via self-amplification of spontaneous emission.

\section{COMPARISON WITH THIRD-GENERATION SYNCHROTRON RADIATION SOURCES}

The third-generation synchrotron radiation sources presently being constructed for use with undulator insertion devices should deliver $10^{3}-10^{4}$ brighter photon beams than storage rings presently in operation. These include the Advanced Light Source at Lawrence Berkeley Laboratory, the Advanced Photon Source at Argonne National Laboratory, the European Synchrotron Radiation Facility at the Institute Louis Langeviri, and the Super Photin Ring-8 at Himeji, Japan. However, the low transverse emittance designs of these storage rings restricts the average circulating current. Thus, while undulators spontaneously radiate much brighter beams than do bending magnets, they do not deliver significantly more average power.

By emitting stimulated emission, FELs produce much brighter beams and, especially those driven by $n$ linacs, can produce higher average-power per unit spectral bandwidth as well. Figure 6 presents a comparison of the predicted time-averaged spectral brightness (photons $/ \mathrm{s} /(\mathrm{mm}-\mathrm{mr})^{2}$ per $0.1 \%$ bandwidth) delivered to a target as a function of wavelength, and Table 6 lists the flux and power output at $100 \mathrm{~nm}$ predicted for an $\mathrm{r}$-linac-FEL for comparison with that of two storage-ring devices. At $10 \mathrm{eV}(124 \mathrm{~nm})$ the FEL will produce $10^{4}$ to 106 higher average spectral flux on target; at $100 \mathrm{eV}(12 \mathrm{~nm})$, the FEL advantage will decrease to a factor of $10^{2}$ to 104 , depending on the FEL duty factor. Moreover, the corresponding peak flux output of the ritinac FEL (@ $1 \%$ duty) will exceed that of synchrotron undulators by an additional factor of 103 . The much higher spectral radiance of FELs argues for their development.

\section{DEVELOPMENT SCHEDULE}

Prior to building the complete user facility, the Los Alamos FEL team will conduct a series of FEL oscillator demonstrations at progressively shorter wavelengths, the first of which will be from 50 to $100 \mathrm{~nm}$. Overall, it appears that the electron-beam, undulator, and mirror technologies are now sufficiently developed to support 


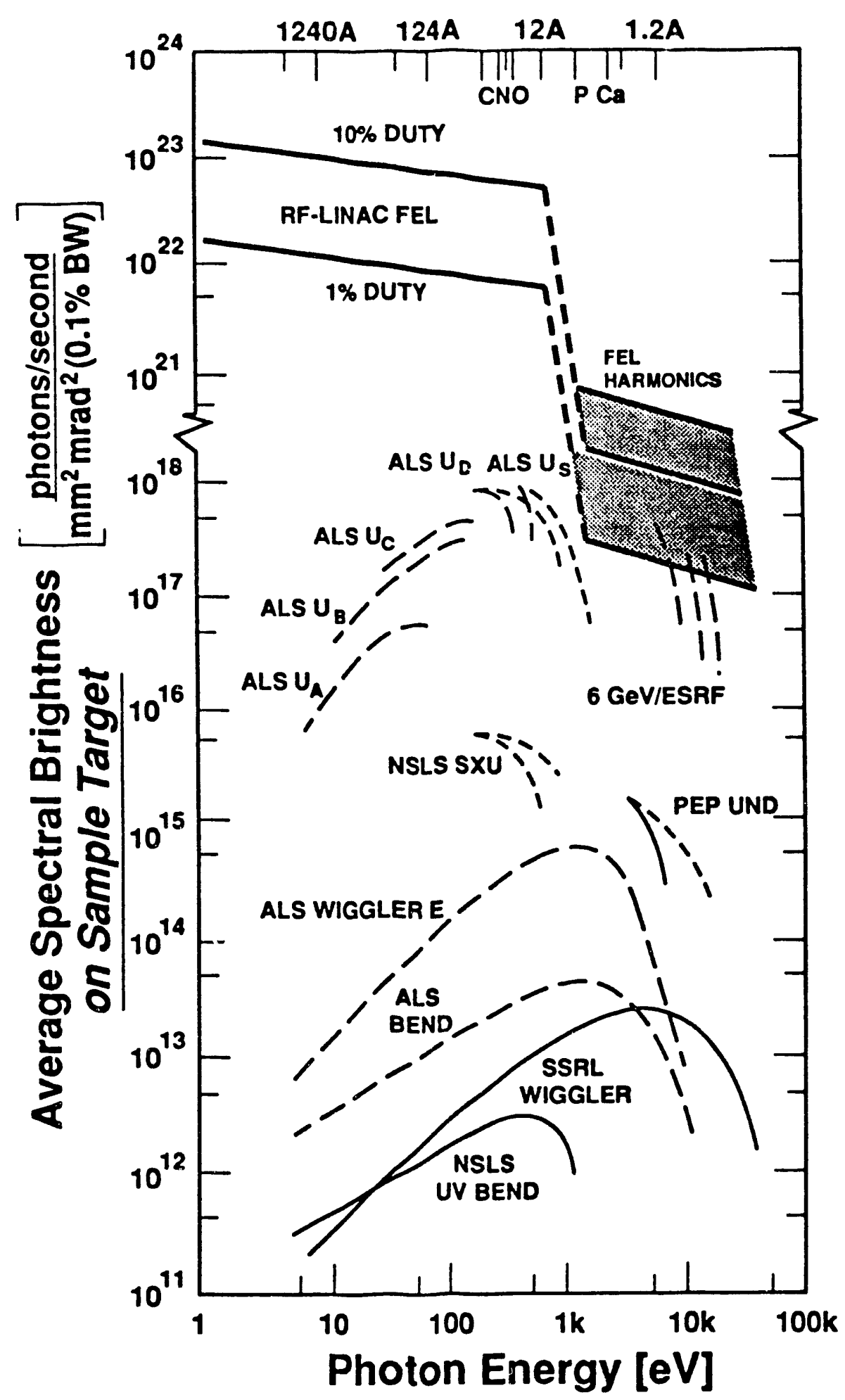

Figure 6. Time-average spectral brightness (delivered on target) of FELs will far exceed that of the most powerful storage rings designed with insertion devices (undulators and wigglers). The FEL curves were calculated for the Los Alamos ri-linac FEL design, and a monochromator efficiency of $10 \%$ was applied to the published undulator output curves. To convert the time-average curves to peak values, the appropriate conversion factors are $3 \times 105$ for the FEL @ 1\% duty and $\sim 3 \times 10^{2}$ for the storage-ring insertion devices. 
such experiments. However, there are still some required prototype demonstrations for the electron beam and optical components. Concerning the electron beam, it will be necessary to preserve the $\sim 1011 \mathrm{~A} /(\mathrm{m}-\mathrm{rad})^{2}$ brightness of the beam delivered by the photoinjector as it is accelerated up to energies $>100 \mathrm{MeV}$ and to develop a long-life photocathode that has sufficient quantum efficiency $\sim 1 \%$. Optical elements needing development include engineering design and test of the XUV ring resonator with multifacet mirrors, measurement of multifacet mirror reflectance for wavelengths $<35 \mathrm{~nm}$, and demonstration of the viability of in situ renewal of multifacet mirror coatings. It will also be necessary to demonstrate operation of two XUV FELs in a series configuration.

The second-phase objective will be to operate an FEL oscillator in the 10- to 14-nm region, corresponding to the high-reflectance band of a Rh multifaceted mirror.23,59 This will require higher electron beam energy (additional accelerator structure) and an brighter electron beam possible only with a photocathode irijector. Since the reflectance of mirrors below $10 \mathrm{~nm}$ is not high enough for laser oscillators, the objective of the third phase will be to produce coherent, 1- to $10-\mathrm{nm}$ radiation by use of a regenerative amplifier consisting of a very long amplifier undulator with partial feedback by use of low-reflectance $(\sim 20 \%)$ mirrors. Successful completion of these three stages will enable the short-wavelength portion of the FEL facility io cover the entire 1- to $600-\mathrm{nm}$ range with the projected output radiation characteristics given previously in Tables 4 and 5 . As with all proposed major facilities, sufficient funding must be obtained to support the conduct of these demonstration experiments 2s well as the construction of the proposed facility.

\section{Table 6. Comparison of if-linac-driven FEL and synchrotron radlation sources at $100 \mathrm{~nm}$}

\begin{tabular}{|c|c|c|c|}
\hline & $\begin{array}{c}\text { SSRL } \\
\text { WGGLEB a }\end{array}$ & $\begin{array}{l}\text { ALS } \\
\text { UNDULATOR b }\end{array}$ & $\begin{array}{l}\text { RF-LINAC } \\
\text { XUVFEL C }\end{array}$ \\
\hline $\begin{array}{l}\text { Spectral flux } \\
\text { (Photons/sec) } \\
\text { at target }\end{array}$ & 1013 & $4 \times 10^{14}$ & 1019 \\
\hline $\begin{array}{l}\text { Average power }(W) \\
\text { at target }\end{array}$ & $10-5$ & $10-3$ & 20 \\
\hline $\begin{array}{c}\text { Peak power }(W) \\
\text { at target }\end{array}$ & $10^{-2}$ & $10^{-1}$ & $10^{\bar{T}}$ \\
\hline $\begin{array}{l}\text { Average \& peak } \\
\text { spectral brightness } \\
\text { at target } \\
\text { (photons/sec/(mm-mr)2/bw) }\end{array}$ & 1012,1015 & 1016,1019 & 1022,1028 \\
\hline $\begin{array}{l}\text { Stanford Synchrotron Re } \\
0.1 \% \text { spectral bandwidth } \\
\text { b Predicted performance o } \\
\text { Lawrence Berkeley Labo } \\
0.1 \% \text { spectral bandwidth } \\
\text { c Single-pass, } \mathrm{f} \text {-linac FEL } \\
\text { driven by a } 500-M e V \text { bee } \\
\text { FEL spectral bandwidth }\end{array}$ & $\begin{array}{l}\text { Laboratory w } \\
\text { nonochromato } \\
\text { ator U8.0 des } \\
58 \\
\text { nonochromato } \\
\text { ed at } 180 \mathrm{MeV} \\
\text { \%, limited by } \mathrm{n}\end{array}$ & $\begin{array}{l}\text { 6 efficiency. } \\
\text { he Advanced Ligl } \\
\text { officiency. } \\
\text { duty factor. Multi } \\
\text { ise. }\end{array}$ & $\begin{array}{l}\text { ce (ALS) storage ring at } \\
\text { d FEL powers by } 10 X \text { if }\end{array}$ \\
\hline
\end{tabular}

\section{SUMMARY}

Free-electron lasers represent the next generation of coherent-radiation sources with peak- and averagepower output capabilities that should surpass those of any existing, continuously tunable photon sources by 
many orders-of-magnitude. Recent successes in the development of FEL component technologies (electron injector, resonator mirrors, and magnetic undulator) should enable these devices to operate in the XUV from $<4$ $\mathrm{nm}$ to $100 \mathrm{~nm}$ as well as at more easily achieved longer wavelengths. These include the high-brightness photoinjector, multifaceted resonator mirrors with retroreflectance $>40 \%$, and high-precision undulators with $>200$ periods. An $\mathrm{n}$-linac-based, multiple-FEL user facility, spanning wavelengths from $1 \mathrm{~nm}$ to $100 \mu \mathrm{m}$, has been designed and is proposed by Los Alamos National Laboratory for scientific research and those industrial applications requiring expanded photon-parameter ranges.

\section{ACKNOWLEDGMENTS}

Discussions with members of the Los Alamos Free-Electron Laser team, in addition to the coauthors listed, were invaluable in preparing this manuscript. Particular thanks go to Scott Volz regarding photocathode lifetime measurements and Donald Feldman for characterization of the operation of the Los Alamos infrared FEL. The staff of the LOS Alamos office of Merrick \& Company and James Allen and Randy Parks of the LANL Engineering Division provided competent facility design expertise for which the Los Alamos institutional support of John Browne, Allen Hartford, Fred Morse, Reed Jensen, and Eugene Wewerka was essential. Special thanks go to Ryszard Gajewski, Director of Division of Advanced Energy Projects of the Department of Energy's Office of Basic Energy Sciences, for supporting the FEL theory and design, development of the multifaceted resonator mirrors, identification of potential applications, and sustained encouragement. Finally, we are indebted to the large number of scientists at Los Alamos and at other institutions that have forecast publicly how XUV-IR FEL radiation could make a significant impact on their respective disciplines.

\section{APPENDIX:}

\section{DEVELOPMENT OF FEL TECHNOLOGIES REQUIRED FOR OPERATION IN THE XUV}

Although FELs as a class must yet be reduced in wavelength by a factor of 2.5 from the short-wavelength operating record of $240 \mathrm{~nm}$ for an FEL oscillator60 to enter into the XUV region, significant improvements of the primary components (eiectron beam, undulator, and resonator mirrors) are either ready for implementation or have been conceived and provide confidence that lasing at such wavelengths is feasible.

\subsection{High-brightness photolnjector}

As was emphasized in the Introduction, the future operation of an FEL oscillator in the XUV will require that the a very bright electron beam (defined as $2 X$ ratio of peak current and normalized emittance-squared). As an example, Goldstein et al.24 determined from 3-D numerical simulations that a 12-nm FEL oscillator will require a beam brightness of $1.2 \times 1011 \mathrm{~N}(\mathrm{~m}-\mathrm{r})^{2}$, corresponding to a peak current of $300 \mathrm{~A}$ and normalized transverse emittance of $23 \pi \mathrm{mm}-\mathrm{mr}$ ( $90 \%$ of particles), with energy spread of $0.1 \%$ (FWHM) at $535 \mathrm{MeV}$. Until the development and experimental demonstration of the laser photoinjector by Fraser and Sheffield,28-31 electron beams with such high brightness had not been generated in an $f$ linac. [The beam brightness capabilities of thermionic, dispenser, and semiconductor photocathode injectors are $0.08,2$, and $30 \times 10^{11} \mathrm{~A} /(\mathrm{m}-\mathrm{rad})^{2}$, respectively. ${ }^{31]}$

The photocathode is positioned on the end wall of the first accelerating cavity of the linac injector where it is irradiated by a train of ps-duration, visible to ultraviolet laser pulses. By applying a very high accelerating gradient, e.g., $30 \mathrm{MeV} / \mathrm{m}$, the photoelectrons attain a relativistic energy of 1 to $>3 \mathrm{MeV}$ in the first cavity, thereby minimizing their susceptibility to perturbations that cause emittance growth. Photocathodes with varying levels of quantum efficiencies (QE), depending on the exposure wavelength, are being used in FEL injectors: $\mathrm{CsK}_{2} \mathrm{Sb}(\leq 10 \% \mathrm{QE})$ at Los Alamos National LaSoratory, 12,13 copper $(<0.1 \% \mathrm{QE})$ at Brookhaven National Laboratory, 61 and $\mathrm{LaB}_{6}(0.01 \% \mathrm{QE})$ at Stanford University. 62 
The $\mathrm{CsK}_{2} \mathrm{Sb}$ cathode is most susceptible to poisoning by contamination and must be operated in high vacuum of $10^{-10}$ Torr in order to have a practical lifetime with $Q E>1 \%$. Recent lifetime measurements of this cathode, while mounted within the photoinjector cavity at $2 \times 10^{-10}$ Torr and without laser irradiation, indicated that the QE declined only by $-10 \%$ in a 36 -hour period followed by no change until the test ended at 68 hours.63 However, in the presence of full $\mathrm{r}$-drive power, Los Alamos experimenters found that CsK $\mathrm{SSb}^{\mathrm{S} b}$ photocathodes have lifetimes limited to one to two days. The degradation occurs only when the accelerating if power is applied. It is suspected that water vapor and carbonaceous gas compounds, desorbed from the cavity walls of the photoinjector, poison the cathode. Los Alamos scientists have determined that the lifetime of semiconductor photocathodes can be increased by by exposing the photoinjector accelerating cavities to high if fields for long periods, and an 18-hour lifetime with full rf-drive power was obtained at a given laser intensity. 30 The effective lifetime has been extended even more by raising the drive-laser power level enough to compensate for the declining quantum efficiency. Glow-discharge cleaning of the cavity walls is now being implemented to augment electron-beam desorption of contaminant gases.

It appears that semiconductor photocathodes with high quantum efficiency are more susceptible to degradation by contamination than metal photocathodes, such as $Y$ and $\mathrm{Cu}$. However, to generate electron pulses with large charges, e.g. 3-4 nC/pulse to attain the desired 300-400 A peak current in 10-ps pulses, it is necessary to have the product of the drive-laser pulse energy and $\mathrm{QE}$ be sufficiently large. The experience of the Los Alamos FEL team is that a photoinjector with a CsK ${ }_{2} \mathrm{Sb}$-cathode irradiated with $532-\mathrm{nm}$ laser pulses produces a micropulse charge of $Q(n C / p u l s e)=4.5 \mathrm{QE}(\%) \times E(\mu \mathrm{J} / \mathrm{pulse}) .12$ Although it becomes increasingly difficult and expensive to generate higher-energy, Cw-modelocked laser pulses, it is possible to use lower-QE cathodes with longer lifetimes with a more powerful drive laser. If the thermal emittance of the electrons leaving the cathode does not become dominant, a shorter drive laser wavelength, $\theta .9 .355 \mathrm{~nm}$, may be used to increase both the QE and lifetime.

The concentrated efforts of several research groups 13,61,62 to implement photoinjectors on if linacs designed for FELS should eventually make if linacs reliable sources of high-current, low-emittance electron beams. If the high brightness of such beams can be maintained without degradation during acceleration to high energy, then numerical simulations predict that FEL gain should be high enough for oscillator operation at wavelengths as short as $4 \mathrm{~nm} .24,27$ A high-current photoinjector has been integrated into the Los Alamos infrared FEL. As reported by Feldman et al., 11 measurements of the beam quality at $17 \mathrm{MeV}$ were in agreement with predicted values for the normalized design emittance, $\sim 30 \pi$ and $40 \pi \mathrm{mm}-\mathrm{mr}$ ( $90 \%$ of electrons) for $2-\mathrm{nC}$ and 5-nC bunches, respectively.

\section{$9.2 \quad$ Long, short-perlod, magnetlc undulators}

Long, high-precision magnetic undulators will be needed to attain sufficient gain for single-pass FEL amplifiers to overcome the resonator mirror and output coupling losses in FEL oscillators. Increasing the number of undulator periods results in higher gain, but the cumulative influence of uncorrected random magnet errors increases with length as well. To prevent serious degradation in FEL gain, the magnitude of individual magnet errors (strength and orientation) that can be tolerated decreases as the number of undulator periods increases, e.g. to below $0.1 \%$ for several hundred periods. 64,65 Fortunately, several solutions for this problem have been devised. Elliott and McVey65 determined that the effect of magnet imprecision as large as $0.7 \%$ can be mostly overcome by measuring the beam position at a sufficiently large number of points along the undulator, e.g. every 25 periods, and by applying a like number of correction fields. Warren 39,40 has developed a very sensitive pulsed-wire field-measuring technique that has proven useful in rapidly indicating the location and magnitude of needed corrections to reduce steering errors to a low level. Subsequently, Feldman and Warren $\mathbf{4 1}$ have wedded this system with a series of field-correcting dipole coils using computer control. From a series of rapid, on-line measurements of the field errors, an automatic correction is applied. This system is expected to prove invaluable for monitoring and correcting magnetic-field errors that may develop while the undulator is in use.

Attainment of high-precision uniformity of undulator magnetic fields has also been demonstrated by several other groups. Curtin et al. 32 used the technique of simulated annealing to computationally determine the opti- 
mum ordering of the individual $\mathrm{SmC}_{5}$ magnets within a 2-m-long undulator in order to minimize the trajectory wander. A deviation of less than $25 \mu \mathrm{m}$ was obtained for a $40-\mathrm{MeV}$ beam and 3.3-kG axial undulator field. Gottschalk et al., 33 have demonstrated a correction technique that that can reduce the rms field errors to only $0.1 \%$ by placing thin iron shims on individual magnets. Another effective scheme devised by Ramian et al.34 uses a moving, robotic screwdriver to individually adjust the magnetic fields in response to measurements of field imperfections.

Since a photoinjector offers the promise of at least an order-of-magnitude increase in beam brightness over thermionic guns, it appears possible that FELs might be operated at a given wavelength with much lower electron beam energies than heretofore. Lower beam energies will directly reduce ihe accelerator length and cost which is essential if FELs are to become affordable for a wide range of applications. To this end, a number of groups are trying to build undulators with very short periods, e.g. 1-10 mm, while keeping the product of the peak axial magnetic field and undulator period near $1 \mathrm{~cm}$-Tesla to maintain high FEL gain. Warren 35 has identified the pulsed electromagnet as a promising design for this objective. The minimum period of such undulator designs is $\sim 1 \mathrm{~mm}$, limited mainly by thermal transport away from the magnet wires, and the number of periods (which sets the tolerable limit on electron energy spread in an FEL) is limited by the necessity of applying periodic correction fields and the ripple in the pulsed current supply. The rate of thermal transport limits the repetition frequency of this wiggler and thus the average power of the FEL. Warren's new slotted tube version of the pulsed microwiggler should increase the therma! transport. 36

Superconducting undulators are of interest because they can be run continuously and are capable of achieving an undulator parameter $\mathrm{K}$ near unity with periods of $1 \mathrm{~cm}$ and less for usefully large magnet gaps. $37 \mathrm{~A}$ superconducting undulator, as realized by Ben Zvi et al. ( $8.8 \mathrm{~mm}$ period and $0.51 \mathrm{~T}$ on-axis field) 38 may be especially well suited for a scientific user facility where cw operation is desired and where maximum stability of the lasing wavelength is required. If such an undulator can be constructed with several hundred periods or more, it may permit the electron energy of the $n$ linac needed for XUV FEL operation below $10 \mathrm{~nm}$ to be scaled down from the present1-GeV design.

\subsection{Resonator mirrors for XUV FELs}

FEL oscillator operation in the XUV will require resonator mirrors with sufficiently high retroreflectance to provide a substantial advantage over a single-pass amplifier. By setting the reflectance requirement at an arbitrary value of $\geq 40 \%$ for each of the two end mirrors, the resonator losses can be offset by a single-pass gain of $>600 \%$, which is attainable.

Below $100 \mathrm{~nm}$, few materials have reflectance exceeding $40 \%$ for normal incidence. For wavelengths from 60-100 nm, polished chemically vapor-deposited (CVD) silicon carbide (SiC), deposited on hot SiC substrates, exhibits a reflectance between $35-40 \%$ at normal incidence.66,67 From $80 \mathrm{~nm}$ to $100 \mathrm{~nm}$, the reflectance of unoxidized Al films increases with wavelength from $40 \%$ to $>90 \% .68$ Elemental metal surfaces of Pt, Ir, Os, and $\mathrm{Au}$, depending on surface condition, have reflectance no higher than $25 \%$ down to $55 \mathrm{~nm}$, falling rapidly a shorter wavelengths. For shorter wavelengths $\leq 20 \mathrm{~nm}$, a fow multilayer mirror designs have useful normalincidence reflectance. In the range from 4.5 to $10 \mathrm{~nm}$ multilayer reflectors of Ru/ $\mathrm{B}_{4} \mathrm{C}$ have been produced with reflectance up to $20 \%, 69$ and in the $14-20 \mathrm{~nm}$ range, multilayer Mo/Si mirrors reflect from $40 \%$ up to $\sim 60 \% .70$

In addition to sufficiently high reflectance to minimize the FEL gain requirements, the total beam-induced thermal distortion of the mirror surfaces must be restricted to a small fraction $(\sim 1 / 4)$ of the operating wavelength. Thus, high mirror reflectance $\geq 95 \%$, i.e., absorptance $\leq 5 \%$, is essential. 24,56 The multifacet XUV metal mirror design proposed by Newnam 42,71 and shown in Fig. 7 should satisfy both requirements in the spectral regions where retroreflectance $\geq 40 \%$ and absorptance $\leq 5 \%$ per facet is obtained. This mirror system exploits the phenomenum of total external reflectance (TER) at large angles of incidence. As pointed out by Vinogradov et al., 72 materials with refractive index (both real and imaginary parts) sufficiently less than unity can provide surprisingly high retroreflectance by using a sequence of reflections beyond the critical angle, typically larger than $60^{\circ}$. Unoxidized $\mathrm{Al}$ and crystalline Si, for example, have the necessary optical constants to attain $\geq 40 \%$ retroreflectance from $35 \mathrm{~nm}$ to $100 \mathrm{~nm}$. 


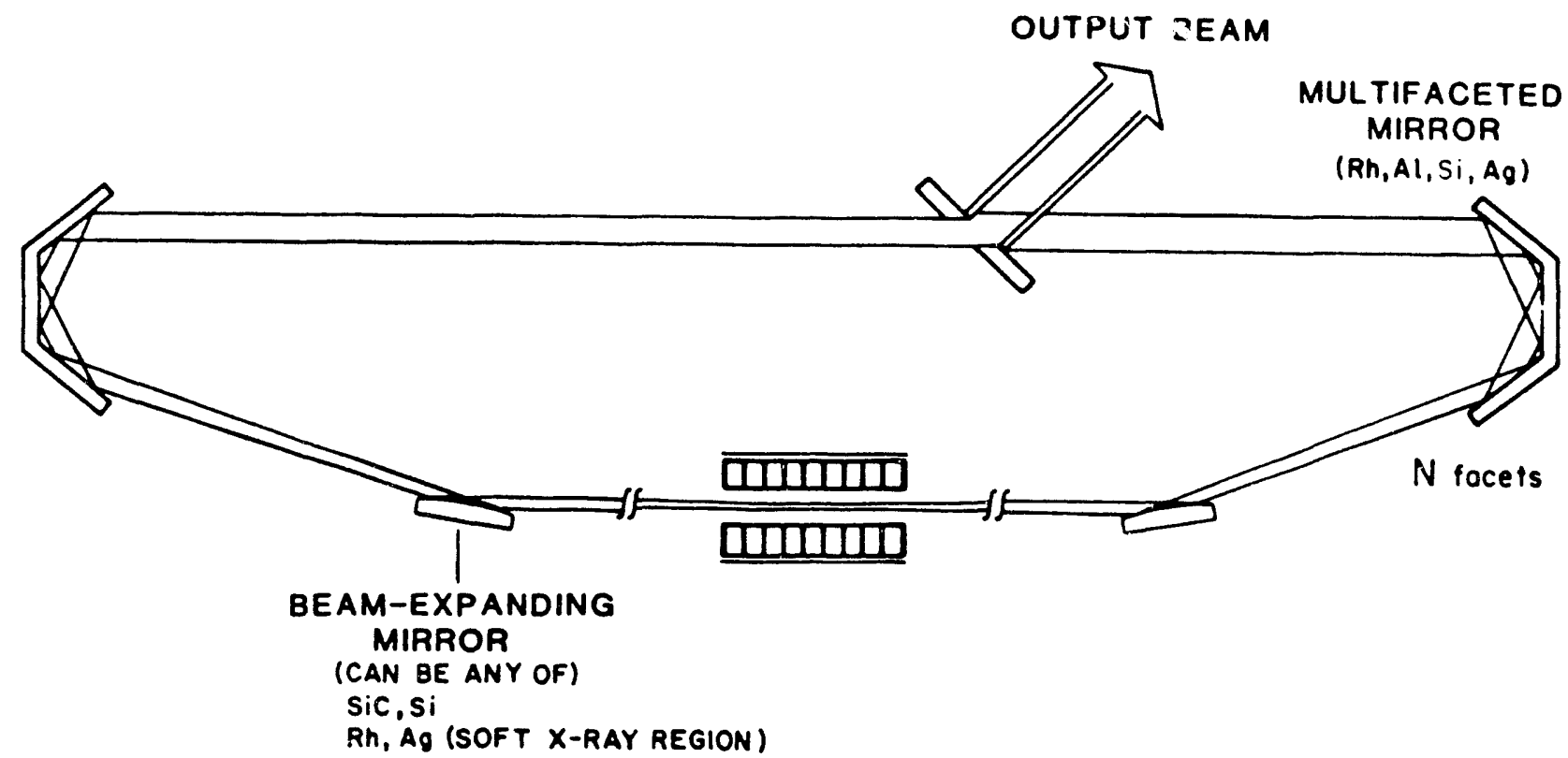

Figure 7. Multifacet, all-metal mirrors based on total extemal reflectance at large angles of incidence $\left(\sim 80^{\circ}\right)$ can provide the necessary $\geq 40 \%$ retroreflection for FEL ring oscillators over broad spectral ranges in the XUV. Intracavity, grazing incidence, hyperboloidal mirrors diverge the beam to reduce beam-induced thermal distortion on the multifacet mirrors and allow shorter resonator lengths. The off-axis paraboloidal figure of the upper facet of the multifacet mirrors collimates the reflected beam. After Newnam. 42

The seven oscillators of the Los Alamos XUV-Vis FEL series, shown in Fig. 2, each have a ring resonator incorporating multifaceted retroreflectors. The appropriate reflective coatings will depend on the spectral operating range: $\sim 35-100 \mathrm{~nm}$ using Al films or crystalline silicon, and 9-14 nm with Pd, $\mathrm{Ag}$, $\mathrm{Ru}$, and $\mathrm{Rh}$ films.42,59,68,72 For wavelengths between 9 and $35 \mathrm{~nm}$, other single-layer films that could exhibit sufficiently high TER iinclude $Y$ and Se.73 Their use in specific FEL oscillators over spectral ranges where their multifacet reflectance is $\geq 40 \%$ is indicated in Table 3 . An important advantage of these single-layer reflectors is that they can be deposited (and renewed) on the multifaceted Si or SiC mirror substrates without removing them from the ring resonator.

Los Alamos researchers have experimenied primarily with aluminum thin films deposited with an electron gun on polished silicon substrates in an ultra-high yacuum (UHV) of -10-10 Torr to minimize surface oxidation. At $58.4 \mathrm{~nm}$ using a He-discharge source and $80^{\circ}$ incidence, Scott74 measured the in situ reflectance of single, Al-coated mirrors to be $98.7 \pm 2 \%$. Under similar conditions, the net retroreflectance of a nine-facet Al-coated retroreflector, was $89 \pm 3 \%$, in agreement with the single-facet measurement. This value of retroreflectance is more than a factor-of-two higher than reported for any other XUV mirror in the vicinity of $60 \mathrm{~nm}$. At $30.4 \mathrm{~nm}$, additional UHV single-mirror measurements indicated that this same nine-mirror array should have a retroreflectance value of $\sim 33 \%$. As evident in Fig. 8 , these measured retroreflectance values actually exceeded those computed using literature values for the Al optical constants, 68 indicating that our films were more ideal.

Contamination of the resonator mirrors must be prevented and/or controlled in the FEL oscillators. Mirror contamination will reduce the reflectance, raise the gain threshold for lasing, and decrease the steady-state output power. Additionally, contaminated external beam-steering mirrors will reduce the useful power on target for either oscillator or amplifier configuration, and excess absorption of the incident energy will distort the mirror surface figure, thereby degrading the beam brightness. Fortunately, at sufficient vacuum levels with low oxygen and water partial pressures, the oxidation of aluminum films proceeds at a slow rate. For example, a two-week exposure of a fresh aluminum film in a $2 \times 10^{-9}$ Torr vacuum, primarily with residual He, resulted in formation of only $1 / 4$ of an oxide monolayer (see Fig. 9).75 Measurements after four weeks indicated that negligible additional growth of the oxide layer had occurred.76 


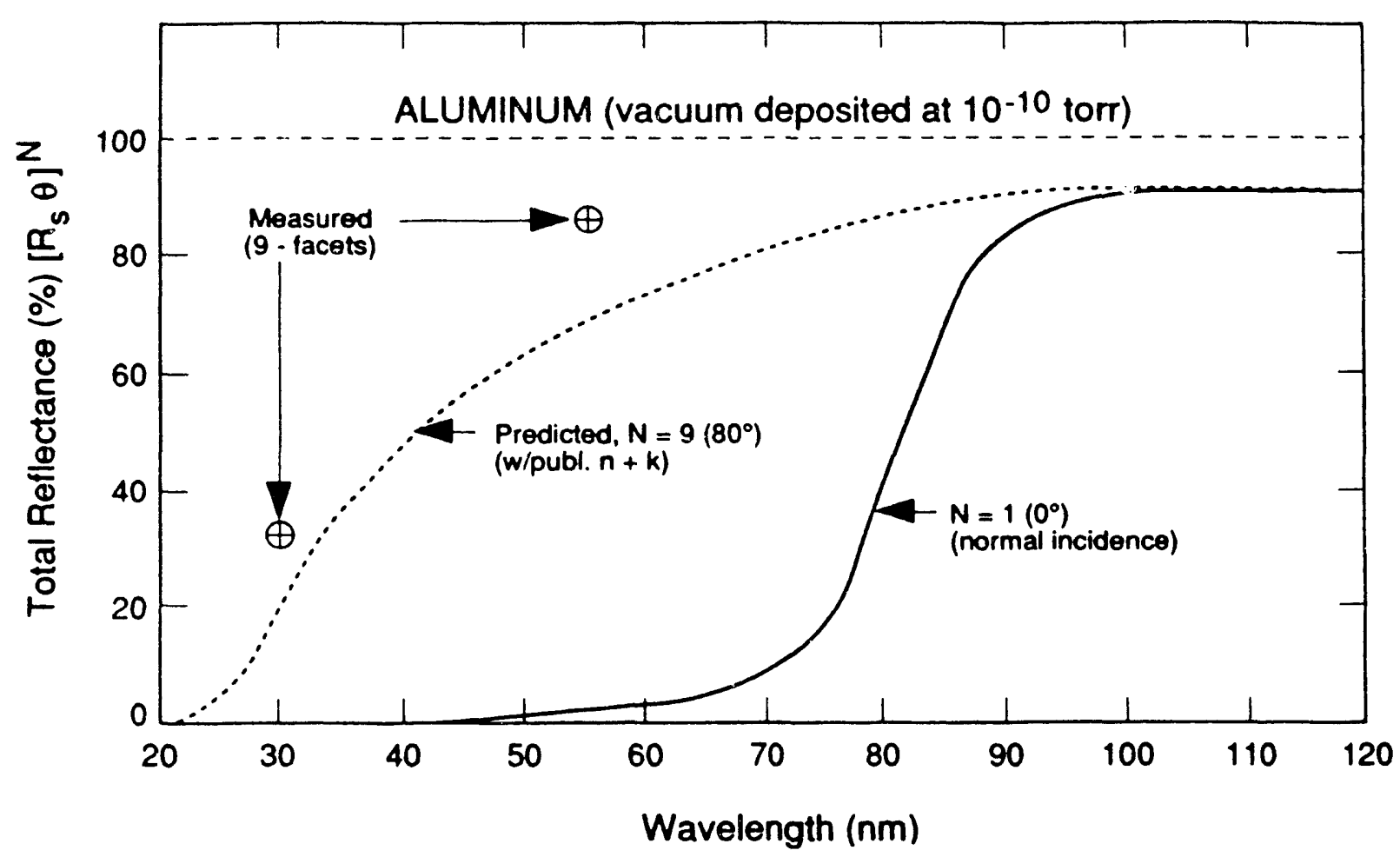

Figure 8. The measured retroreflectance 74 at 30.4 and $58.4 \mathrm{~nm}$ of a nine-faceted aluminum retro-mirror (deposited on Si substrates in 10-10 Torr vacuum) verified the predicted performance, based on measured optical constants, 68 and exceeds $40 \%$ for wavelengths greater than $35 \mathrm{~nm}$.

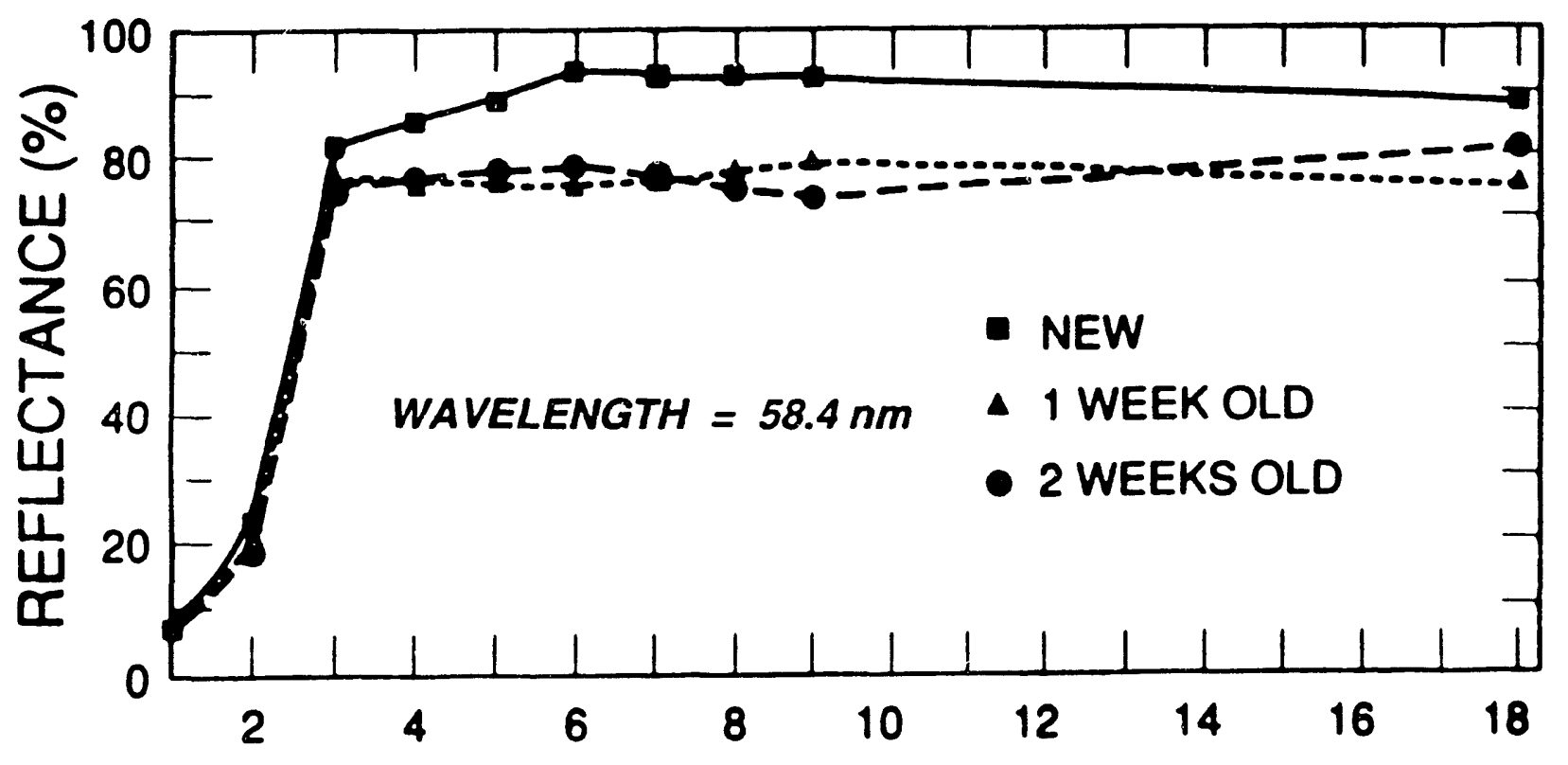

NUMBER OF FACETS

Figure 9. Net retroreflectance vs number of facets of a multifacet aluminum mirror calculated from measured values of reflectance versus angle of incidence for an aluminum film deposited on a Si substrate. This same film was measured again after one and two weeks in a UHV system at a helium pressure of $\geq 2 \times 10^{-9}$ Torr. Little change is seen between one and two weeks. After Scott et al. 75 
Growth of carbon contaminant films on the areas of the reflectors exposed to the XUV beam is a concern. A valuable review of this carbon problem and its mitigation has been published by Rehn. 77 it is possible that an initial clearing of the UHV system of carbonaceous compounds by using the $r$-discharge technique developed by Johnson et al., 78,79 (followed by in situ deposition of the reflecting films) will yield adequately long lifetimes with high reflectance. Another option is to periodically overcoat the contaminated metallic films with fresh material to offset the effects of gradual deterioration that may occur while in the FEL resonator. Of course, the total thickness of the films must not become too great lest surface roughness increase. An ion gun, mounted in the vacuum chamber and used with specific beam parameters, may be an effective way to periodically sputter away aged films prior to evaporation of a fresh film.

In summary, multifaceted mirrors of certain single-layer metals offer high reflectance over a broad spectral ranges and they can be deposited on the multifaceted Si substrates mounted within the ring resonators. Without breaking vacuum, they can be overcoated or treated with an ion beam to remove the oxide after a period of use. Finally, this retroreflector design is inherently resistant to thermal and optical wavefront distortions, as well as to laser-induced damage. This is due to the high reflectance of S-plane polarized light from metal surfaces at large angles-of-incidence and the $\cos \varnothing$ spatial dilution of the beam intensity over the tilted surfaces. It remains to implement the multifacet mirrors in ring resonators to test predictions of their optical stability. 80

\section{REFERENCES}

1. B. E. Newnam, B. D. McVey, J. C. Goldstein, C. J. Elliott, M. J. Schmitt, K. Lee, T. S. Wang, B. Carlsten, J. S. Fraser, R. L. Sheffield, M. L. Scott, and P. N. Arendt, "Progress toward an RF Linac Free-Electron Laser for the Extreme-Ultraviolet Spectral Region," J. Opt. Soc. Am.-B 3, P144 (1986).

2. B. E. Newnam, "Extension of Free-Electron Lasers into the Extreme Ultraviolet," in Free-Electron Lasers: Critical Review of Technology, B. E. Newnam, Ed., Proc. SPIE Vol. 738,155-175 (1988).

3. B. E. Newnam, "XUV Free-Electron Laser Development at Los Alamos," in Proc. of the 1988 Linear Accelerator Conf. C. Leemann, Ed., CEBAF-Rept. 89-001, pp. 290-294, June, 1989.

4. B. E. Newnam, "Projected Performance of RF-Linac-Driven Free-Electron Lasers in the ExtremeUltraviolet Spectral Region," Nucl. Instr. and Meth. in Phys. Res. B40/41, 1053-1057 (1989).

5. B. E. Newnam, "Free-Electron Laser Sources of Extreme-Ultraviolet Radiation and their Vacuum Requirements," in Vacuum Design of Synchrotron Light Sources, Y. G. Amer, S. D. Bader, A.R.Krauss, and R. C. Niemann, Eds., AIP Conf. Proc. No. 236 (Amer. Inst. Phys., NY, 1991), pp. 278-299.

6. B. E. Newnam, J. C. Goldstein, J. S. Fraser, and R. K. Cooper, " A Linac-Driven XUV Free-Electron Laser," in Free-Electron Generation of Extreme Ultraviolet Coherent Radiation, J. M. J. Madey and C. Pelligrini, Eds., (Amer. Inst. of Phys., Now York, 1984), AlP Conf. Proc. No. 118, 190-202.

7. J. C. Goldstein, B. E. Newnam, R. K. Cooper, and J. C. Comly, Jr., "An XUVNUV Free-Electron Laser Oscillator," in Laser Techniques in the Extreme Ultraviolet, S. E. Harris and T. B. Lucatorto, Eds., (Amer. Inst. of Phys., New York, 1984), AIP Cont. Proc. No. 119, 293-303.

8. D. W. Feldman, R. W. Warren, B. E. Cartsten, W. E. Stein, A. H. Lumpkin, S. C. Bender, G. Spalek, J. M. Watson, L. M. Young, J. S. Fraser, J. C. Goldstein, H. Takeda, T. F. Wang, R. B. Feldman, R. K. Cooper, W. J. D. Johnson, and C. A. Brau, "Recent Results from the Los Alamos Free-Electron Laser," IEEE J. Quantum Electron. QE-23, 1476-1488 (1987).

9. R. W. Warren, J. E. Sollid, D. W. Feldman, W. E. Stein, W. J. Johnson, A. H. Lumpkin, and J. C. Goldstein, "Near-Ideal Lasing with a Uniform Wiggler," Nucl. Instr. and Meth in Phys. Res. A285, 1-10 (1989).

10. D. W. Feldman, "Recent Experiments at the Los Alamos Free-Ele urron Laser," in Free-Electron Lasers II, Y. Petroff, Ed., Proc. SPIE Vol. 1133, 36-53 (1989).

11. D. W. Feldman, S. C. Bender, B. E. Carlsten, J. Early, R. B. Feldman, W. J. D. Johnson, A. H. Lumpkin, P. G. O'Shea, W. E. Stein, R. L. Sheffield, and K. McKenna, "Performance of the Los Alamos HIBAF Accelerator at $17 \mathrm{MeV}, "$ Nucl. Instr. and Meth. in Phys. Res. A304, 224-227 (1991).

12. P. G. O'Shea, S. C. Bender, B. E. Carlsi.n, J. W. Early, D. W. Feldman, R. B. Feldman, W. J. D. Johnson, A. H. Lumpkin, R. L. Sheffield, R. W. Springer, W. E. Stein, and L. M. Young, "Performance of the Photoinjector Accelerator for the Los Alamos Free-Electron Laser," in Proc. of the 1990 Linear Accelerator Conf., Albuquerque, to be publ., 1991. 
13. P. G. O'Shea, S. C. Bender, B. E. Carlsten, J. W. Early, D. W. Feldman, R. B. Feldman, W. J. D. Johnson, A. H. Lumpkin, W. E. Stein, and T. J. Zaugg, "Performance of the Los Alamos Photoinjector-Driven Free-Electron Laser," Nucl. Instr. and Meth. in Phys. Res., to be publ., 1992.

14. S. V. Benson, J. Schultz, B. A. Hooper, R. Crane, and J. M. J. Madey, "Status Report on the Stanford Mark III Infrared Free Electron Laser," Nuc. Instr. and Meth. in Phys. Res. A272, 22-28 (1988).

15. S. V. Benson, W. S. Fann, B. A. Hooper, J. M. J. Madey, E. B. Szarmes, B. Richman, and L. Vintro, "A Review of the Stanford Mark III Infrared FEL Program," Nucl. Instr. and Meth. in Phys. Res. A296, 110-114 (1990).

16. D. H. Dowell, M. L. Laucks, A. R. Lowrey, M. Bemes, A. Currie, P. Johnson, K. McCrary, J. Adamski, D. R. Shoffstall, A. H. Lumpkin, and R. L. Tokar, "Improving Electron Beam Quality of the Boeing Free Electron Laser," Nucl. Instr. and Meth. in Phys. Res. A304, 336-341 (1991).

17. M. L. Laucks, D. H. Dowell, A. R. Lowrey, M. Bemes, A. Currie, P. Johnson, K. McCrary, J. Adamski, D. Pistoresi, D. R. Shoffstall, M. Bentz, R. Burns, R. Hudyma, K. Sun, W. Mower, S. Bender, J. Goldstein, A. Lumpkin, B. McVey, R. Tokar, and D. Shemwell, "Optical Measurements on the Boeing Free Electron Laser Ring Resonator Experiment," Nucl. Instr. and Meth. in Phys. Res. A 304, 25-30 (1991).

18. J. C. Goldstein, B. D. McVey, and B. E. Newnam, "Gain Physics of RF-Linac-Driven XUV Free-Electron Lasers," in Short Wavelength Coherent Radiation: Generation and Applications, D. T. Attwood and J. Bokor, Eds., (Amer. Inst. of Phys., New York, 1986), AIP Conf. Proc. No. 147, pp. 275-290.

19. J. C. Goldstein, B. D. McVey, and B. E. Newnam, "Three-Dimensional Simulations of an XUV FreeElectron Laser," in Int'l. Conf. on Insertion Devices for Synchrotron Sources, R. Tatchyn and I. Lindau, Eds., Proc. SPIE Vol. 582, pp. 350-360 (1986).

20. J. C. Goldstein and B. D. McVey, "Recent Theoretical Results for an RF-Linac-Driven XUV FreeElectron Laser," Nucl. Instr. and Meth. in Phys. Res. A259, 203-209 (1987).

21. B. E. Newnam, "Extension of Free-Electron Lasers into the Extreme Ultraviolet," in Free-Electron Lasers: Ceitical Review of Technology, B. E. Newnam, Ed., Proc. SPIE Vol. 738, 155-175 (1988).

22. J. C. Goldstein, B. D. McVey, and C. J. Elliott, "Conceptual Designs of a $50 \mathrm{~nm}$ FEL Oscillator and a 20-40 nm SASE Amplifier," Nucl. Instr. and Meth. in Phys. Res. A272, 177-182 (1988).

23. B. E. Newnam, "Projected Performance of RF-Linac-Driven Free-Electron Lasers in the ExtremeUltraviolet Spectral Region," Nucl. Instr. and Meth. in Phys. Res. B40/41, 1053-1057 (1989).

24. J. C. Goldstein, B. D. McVey, and B. E. Newnam, "Optical Design and Performance of an XUV FEL Oscillator," Nucl. instr. and Meth. in Phys. Res. A296, 288-291 (1990).

25. J. C. Goldstein, R. W. Warren, and B. E. Newnam, "Design Requirements and Calculated Performance of an XUV FEL Oscillator Operating on a Higher Harmonic," Nucl. Instr. and Meth. in Phys. Res. A304, 449-452 (1991).

26. R. L. Sheffield, "High-Brightness Electron Injectors," in Proc. of the ICFA Workshop on Low Emittance $e^{-}-e^{+}$Beams, J. B. Murphy and C. Pelligrini, Eds., (Brookhaven Nat'l. Lab., Upton, NY, 1987), BNL Rept. 52090, pp. 141-152.

27. J. C. Goldstein, "Electron Beam Requirements for Soft X-Ray/XUV Free-Electron Lasers," in Proc. of the ICFA Workshop on Low Emittance $\theta^{-}-\theta^{+}$Beams, op cit., pp. 180-196.

28. J. S. Fraser and R. L. Sheffield, "High-Brightness Injectors for RF-Driven Free-Electron Lasers," IEEE J. Quantum Electron. OE-23, 1489-1496 (1987).

29. R. L. Sheffield, E. G. Gray, and J. S. Fraser, "The Los Alamos Photoinjector Program," Nucl. Instr. and Meth. in Phys. Res. A272, 222-226 (1988).

30. R. L. Sheffield, W. D. Comelius, D. C. Nguyen, R. W. Springer, B. C. Lamartine, E. R. Gray, J. M. Watson, and J. S. Fraser, "RF Photoelectron Gun Experimental Pertormance," in 1988 Linear Accelerator Conf. Proc., C. Leemann, Ed., CEBAF-Rept.-89-001, pp. 520-522, June, 1989.

31. R. L. Sheffield, "High-Brightness Electron Injectors: A Review," in Proc. of 1989 IEEE Particle Accelerator Conf., F. Bennett and J. Kopta, Eds., IEEE Cat. No. 89CH2669-0 (IEEE Serv. Center, Piscataway, NJ, 1989), Vol. 2, pp. 1098-1102.

32. M. S. Curtin, A. Bhowmik, W. A. McMullin, S. V. Benson, J. M. J. Madey, B. A. Richman, and L. Vintro, "A High Quality Permanent-Magnet Wiggler for the Rocketdyne/Stanford Infrared Free Electron Laser," Nucl. Instr. and Meth. in Phys. Res. A272, 187-191 (1988).

33. S. C. Gottschalk, D. C. Quimby, K. E. Robinson, and J. M. Slater, "Wiggler Error Reduction Through Shim Tuning," Nucl. Instr. and Meth. in Phys. Res. A296, 579-587 (1990). 
34. G. Ramian, "Status and Plans of the UCSB FEL Development Program," unpubl. paper presented at the 11th Intl. FEL Cont. in Naples, FL, Aug. 28-Sept. 1, 1989.

35. S.C. Gottschalk, A. L. Pindroh, D. C. Quimby, K. E. Robinson, and J. M. Slater, "Enhanced FEL Performance from Superconducting Undulators," Nucl. Instr. and Meth. in Phys. Res. A304, $732-737$ (1991).

36. I. Ben-Zvi, R. Fernow, J. Gallardo, G. Ingold, W. Sampson, and M. Woodle, "Pertormance of a SuperConducting, High Field Subcentimeter Undulator," Nucl. Instr. and Meth. in Phys. Res., to be publ. in 1992.

37. R. W. Warren, D. W. Feldman, and D. Preston, "High-Field Pulsed Microwigglers," Nucl. Instr. and Meth. in Phys. Res. A296, 558-562 (1990).

38. R. W. Warren, "Progress with the Slotted-Tube Pulsed Microwiggler," Nucl. Instr. and Meth. in Phys. Res., to be publ. in 1992.

39. R. W. Warren and C. J. Elliott, "New System for Wiggler Fabrication and Testing," in Proc. of the Adriatico Research Conf. on Undulator Magnets for Synchrotron Radiation and Free-Electron Lasers, R. Bonifacio, L. Fonda, and C. Pelligrini, Eds., (World Scientific, Singapore,1988), pp. 28-38.

40. R. W. Warren, "Limitations on the Use of the Pulsed-Wire Field-Measuring Technique," Nucl. Instr. and Meth. in Phys. Res. A272, 257-263 (1988).

41. R. B. Feldman and R. W. Warren, "Fully Automatic Wiggler-Field Test and Correction," Nucl. Instr. and Meth. in Phys. Res. A296, 619-623 (1990).

42. B. E. Newnam, "Multifacet Metal Mirror Design for Soft X-Ray and Extreme-Ultraviolet Free-Electron Laser Resonators," in Laser Induced Damage in Optical Materials: 1985, H. E. Bennett, A. H. Guenther, D. Milam, and B. E. Newnam, Eds., (Natl. Bur. Stand., Wash., DC, 1988), NBS Spec. Publ. 746, pp. 261-269.

43. M. L. Scott, P. N. Arendt, B. J. Cameron, J. M. Saber and B. E. Newnam, "Extreme-Ultraviolet Reflectance Degradation of Aluminum and Silicon from Surface Oxidation," Appl. Opt. 27, 1503-1507 (1988).

44. M. L. Scott, "Reflectance of Aluminum Reflectors in the Extreme Ultraviolet," in OSA Proc. on Short Wavelength Coherent Radiation: Generation and Applications, R. W. Falcone and J. Kirz, Eds., (Opt. Soc. of Amer., Wash., DC, 1988), Vol. 2, pp. 322-324.

45. Physics of Free-Electron-Laser Applications, Special Issue of J. Opt. Soc. Am.-B 6, D. A. G. Deacon, R. F. Haglund, Jr., B. E. Newnam, and H. Schlossberg, Eds., May, 1989.

46. Applications of Free Electron Lasers, Proc. of the Workshop at Castelgandolfo, Italy, D. A. G. Deacon and A. De Angelis, Eds., Nuct. Instr. and Meth. in Phys. Res. A239 No. 3, (1985).

47. Report of the Workshop on Scientific Opportunities for Infrared Free-Electron Lasers, Lawrence Berkeley Lab Rept. LBL-26783, CONF-8810126, Feb., 1989.

48. R. Prazeres, P. Guyot-Sionnest, D. Jaroszynski, J. M. Ortega, M. Billardon, M. E. Couprie, and M. Velghe, "Coherent Harmonic Generation in VUV with the Optical Klystron on the Storage Ring Super-ACO," Nucl. Instr. and Meth. in Phys. Res. A304. $72-76$ (1991).

49. Free-Electron Laser Applications in the Ultraviolet, OSA Tech. Digest Series, Vol. 4, D. A. G. Deacon and B. E. Newnam, Eds., (Optical Soc. Am., Washington, D.C.), March 2-5, 1988.

50. P. Morin, "FEL Applications in the UV," Synchrotron Radiation News 1,11 (1988).

51. C. Yamanaka, "Future Industrial Applications of Free Electron Lasers," Nucl. Instr. and Meth. in Phys. Res., to be publ., 1992.

52. G. R. Neil, J. J. Bisognano, D. Douglas, H. F. Dylla, G. A. Kraft, C. W. Leemann, P. Liger, D. V. Neuffer, C. K. Sinclair, and B. Yunn, "FEL Design Using the CEBAF Linac," Nucl. Instr. and Meth. in Phys. Res., to be publ. in 1992.

53. S. D. Conradson and B. E. Newnam, "Research Opportunities at the Proposed Los Alamos XUV-FEL User Facility," in Free-Electron Lasers and Applications, D. Prosnitz, Ed., Proc. SPIE Vol. 1227, 134-144 (1990).

54. B. E. Newnam, "Extreme Ultraviolet Free-Electron Laser-Based Projection Lithography Systems," Opt. Eng. 30, 1100-1108 (1991).

55. B. D. McVey, "Three-Dimensional Simulations of Free Electron Laser Physics," Nucl. Instr. and Meth. in Phys. Res. A250 449-4.55 (1986).

56. B. D. McVey, J. C. Goldstein, R. D. McFarland, and B. E. Newnam, "Thermal Analysis of Multifacet-Mirror Ring Resonator for XUV Free-Electron Lasers," in Laser Induced Damage in Optical Materials:1990, H. E.

Bennett, A. H. Guenther, L. L. Chase, B. E. Newnam, and M. J. Soileau, Eds., Froc. SPIE Vol. 1441, 457-468, (1991).

57. Report of the ALS/SSRL Users Workshop, May 9-11, 1983, A. I. Bienenstock, T. Elioii, and E. E. Haller, co-chairmen, Lawrence Berkeley Laboratory Pub-5095, 1983. 
58. An ALS Handbook, Lawrence Berkeley Laboratory PUB-643 Rev.2, April, 1989.

59. D. W. Lynch and W. R. Hunter, "Rhodium (Rh)," in Handbook of Optical Constants, E. D. Palik, Ed., (Academic Press, New York, 1985), pp. 342-349.

60. G. N. Kulipanov, V. N. Litvinenko, I. V. Pinayev, V. M. Popik, A. N. Skrinsky, A. Sokolov, and N. A. Vinokurov, "VEPP-3 Storage Ring Optical Klystron: Lasing in Visible and Ultraviolet Regions," Nucl. Instr. and Meth. in Phys. Res. A296, 1-3, (1990).

61. I. S. Lehrman, I. A. Birnbaum, S. Z. Fixler, R. L. Heuer, S. Siddiqi, I. Ben-Zvi, K. Batchelor, J. C. Gallardo, H. G. Kirk, T. Srinivasan-Rao, and G. D. Warren, "Design of a High-Brightness High Duty Factor Photo-Cathode Electron Gun," Nucl. Instr. and Meth. in Phys. Res., to be publ. in 1992.

62. M. Curtin, G. Bennett, R. Burke, A. Bhowmik, P. Metty, S. Benson, and J. M. J. Madey, "First Demonstration of a Free-Electron Laser Driven by Electrons from a Laser-Irradiated Photocathode," Nucl. Instr and Meth. in Phys. Res. A296, 127-133 (1990).

63. S. K. Volz, Los Alamos Natl. Laboratory, priv. commun., 1990.

64. B. M. Kincaid, "Laser Harmonic Generation Using the Optical Klystron and the Effects of Wiggler Errors," Nucl. Instr. and Meth. in Phys. Res. A250, 212-219 (1986).

65. C. J. Elliott and B. McVey, "Analysis of Undulator Field Errors for XUV FELs," in Proc. of the Adriatico Research Conf. on Undulator Magnets for Synchrotron Radiation and Free-Electron Lasers, op. cit., pp.142-165.

66. W. J. Choyke, and E. D. Palik, "Silicon Carbide (SiC)," in Handbook of Optical Constants, op. cit., pp. 587-596.

67. S. Mrowka, P. Jelinsky, S. Bowyer, G. Sanger, and W. J. Choyke, "Reflectivity of Silicon Carbide in the Extreme Ultraviolet," in X-Ray Instrumentation in Astronomy, J. L. Culhane, Ed., Proc. SPIE Vol. 597, 160-164 (1985).

68. D. Y. Smith, E. Shiles and M. Inokuti, "The Optical Properties of Metallic Aluminum," in Handbook of Optical Constants of Solids, op. cit., 369-406 (1985).

69. D. G. Stearns, R. S. Rosen, and S. P. Vernon, "Normal-Incidence X-Ray Mirror for 7 nm," Opt. Lett. 16. 1283-1285, (1991).

70. J. B. Kortright, Lawrence Berkeley Laboratory, reflectance measurements of Mo/Si mirrors, 1989.

71. B. E. Newnam, "Extreme Uttraviolet Reflector," U.S. Patent 4,917,447. Appl. Opt. 30, 3080 (1991).

72. A. V. Vinogradov, I. V. Kozhevnikov, and A. V. Popov, "On Wide-Band Mirrors for Soft X-Ray Range," Opt. Commun. 47, 361-363 (1983).

73. T.-Y. Hung and P. L. Hagelstein, "Investigations of Whisper Gallery Mirrors for Extreme Ultraviolet and Soft X-Rays," in Opt. Soc. Am. Annual Mtng. Tech. Digest 1990, Vol. 15 of the OSA Tech. Digest Series (Opt. Soc. Am., Wash., D.C. 1990), p. 62.

74. M. L. Scott, "Reflectance of Aluminum Reflectors in the Extreme Ultraviolet," in OSA Proc. on Short Wavelength Coherent Radiation: Generation and Applications, R. Falcone and J. Kirz, Eds., (Opt. Soc. Am., Washington, DC, 1988), Vol. 2, pp. 322-324.

75. M. L. Scott, P. N. Arendt, B. J. Cameron, J. M. Saber and B. E. Newnam, "Extreme-Ultraviolet Reflectance Degradation of Aluminum and Silicon from Surface Oxidation," Appl. Opt. 27, 1503-1507 (1988).

76. M. L. Scott, Los Alamos Natl. Lab., priv. commun., 1988.

77. V. Rehn, "Carbon and other Contaminants in Vacuum Systems," in Vacuum Design of Synchrotron Light Sources, op. cit. pp. 235-265.

78. E. D. Johnson, S. L. Hulbert, R. F. Garrett, G. P. Williams, and M. L. Knotek, "In Situ Reactive Glow Discharge Cleaning of X-Ray Optical Surfaces," Rev. Sci. Instrum. 58, 1042-1045 (1987).

79. E. D. Johnson and R. F. Garrett, "In Situ Reactive Cleaning of X-Ray Optics by Glow Discharge," Nucl. Instr. and Meth. in Phys. Res. A266, 381-385 (1988).

80. D. R. Gabardi and D. L. Shealy, "Optical Analysis of Grazing Incidence Ring Resonators for FreeElectron Lasers," in X-Ray/EUV Optics for Astronomy and Microscopy, R. B. Hoover, Ed., Proc. SPIE Vol. 1160, 337-348 (1989).

\section{DISCLAIMER}

This report was prepared as an account of work sponsored by an agency of the United States Government. Neither the United States Government nor any agency thereof, nor any of their employees, makes any warranty, express or implied, or assumes any legal liability or responsibility for the accuracy, completeness, or usefulness of any information, apparatus, product, or process disclosed, or represents that its use would not infringe privately owned rights. Reference herein to any specific commercial product, process, or service by trade name, trademark, manufacturer, or otherwise does not necessarily constitute or imply its endorsement, recommendation. or favoring by the United States Government or any agency thereof. The views and opinions of authors expressed herein do not necessarily state or reflect those of the United States Government or any agency thereof. 

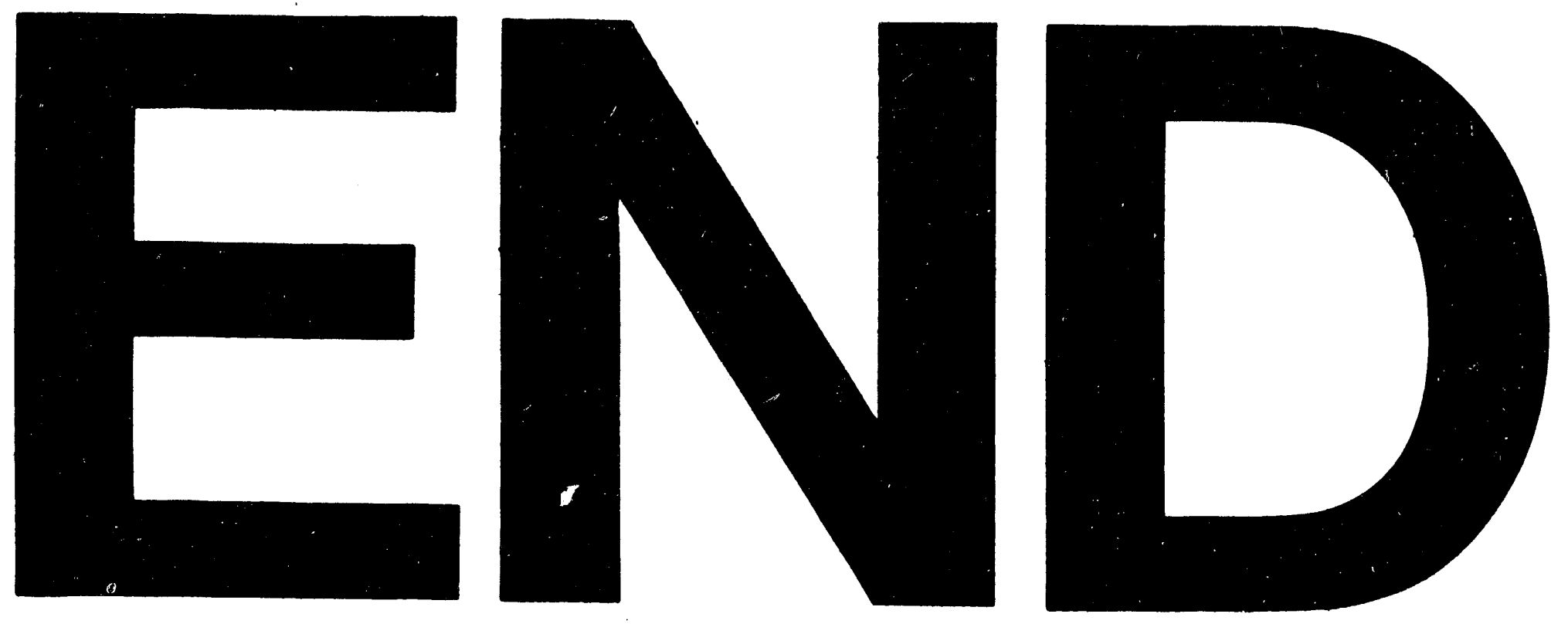

$\Rightarrow$
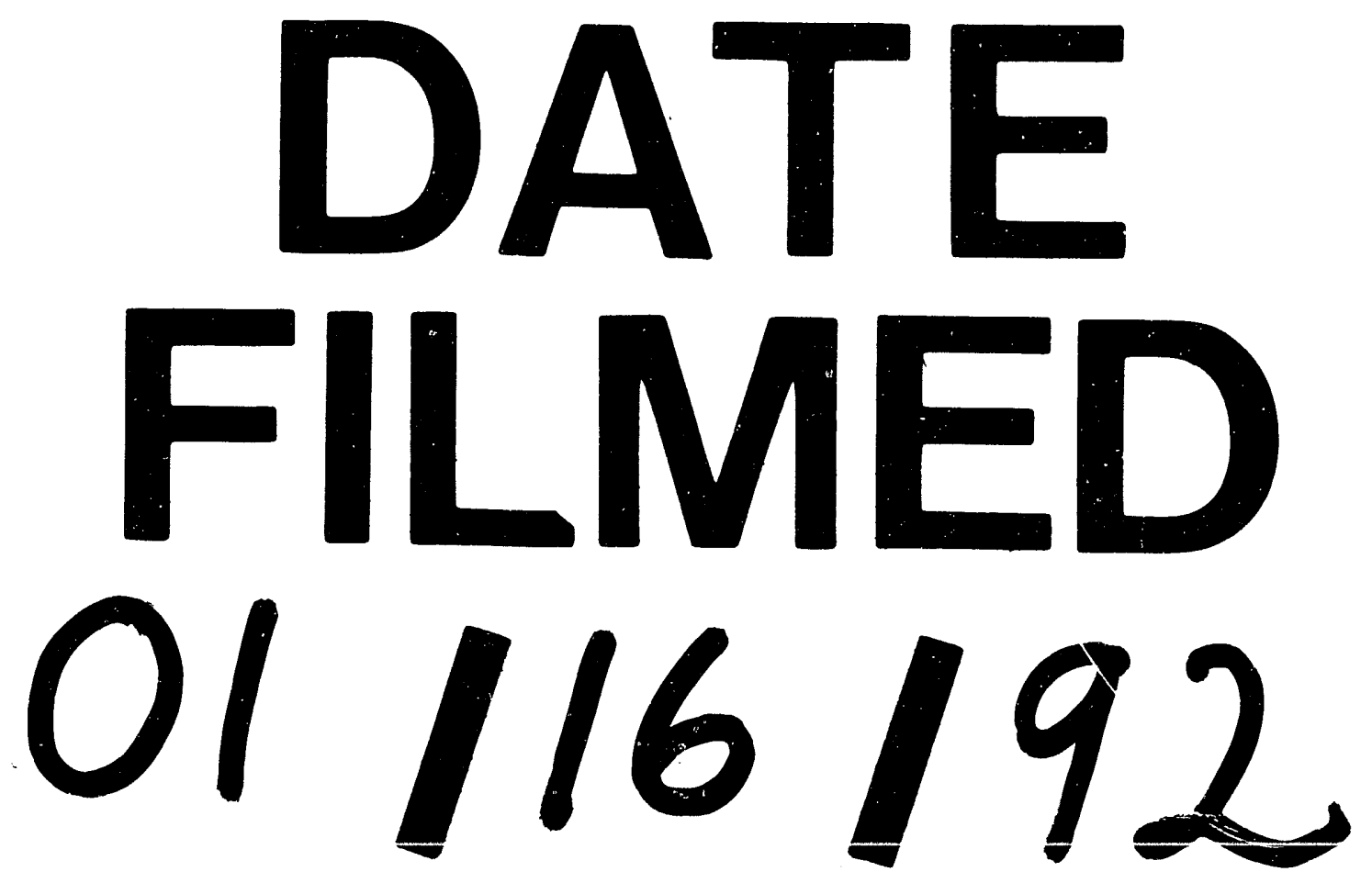
